\title{
FIRMS, DESTINATIONS, AND AGGREGATE FLUCTUATIONS
}

\author{
By Julian di Giovanni, ANDRei A. Levchenko, AND Isabelle MeJean ${ }^{1}$
}

\begin{abstract}
This paper uses a data base covering the universe of French firms for the period 1990-2007 to provide a forensic account of the role of individual firms in generating aggregate fluctuations. We set up a simple multisector model of heterogeneous firms selling to multiple markets to motivate a theoretically founded decomposition of firms' annual sales growth rate into different components. We find that the firm-specific component contributes substantially to aggregate sales volatility, mattering about as much as the components capturing shocks that are common across firms within a sector or country. We then decompose the firm-specific component to provide evidence on two mechanisms that generate aggregate fluctuations from microeconomic shocks highlighted in the recent literature: (i) when the firm size distribution is fat-tailed, idiosyncratic shocks to large firms directly contribute to aggregate fluctuations, and (ii) aggregate fluctuations can arise from idiosyncratic shocks due to input-output linkages across the economy. Firm linkages are approximately three times as important as the direct effect of firm shocks in driving aggregate fluctuations.
\end{abstract}

KEYWORDS: Aggregate fluctuations, firm-level shocks, large firms, linkages.

\section{INTRODUCTION}

A LONG TRADITION IN MACROECONOMICS SEEKS to understand the microeconomic underpinnings of aggregate fluctuations. Starting with the seminal work of Long and Plosser (1983), an important line of research explores the role of sectoral shocks in generating aggregate fluctuations (see, e.g., Stockman (1988), Foerster, Sarte, and Watson (2011), Carvalho and Gabaix (2013), among many others). A running theme in this literature is that idiosyncratic shocks to a single sector can have sizeable aggregate effects if the sector is strongly interconnected with others in the economy through input linkages (Horvath (1998, 2000), Dupor (1999), Shea (2002), Conley and Dupor (2003), Acemoglu, Carvalho, Ozdaglar, and Tahbaz-Salehi (2012)). The role of individual firms in the aggregate business cycle has received comparatively less attention. Gabaix (2011) argues that because the firm size distribution is extremely fat-tailed (the economy is "granular"), idiosyncratic shocks to individual (large) firms will not average out and, instead, lead to movements in the

\footnotetext{
${ }^{1}$ We would like to thank a co-editor, two anonymous referees, George Akerlof, Gilles Duranton, Jonathan Eaton, Chris House, Ayhan Kose, Kory Kroft, Julien Martin, Akito Matsumoto, Ryan Monarch, Peter Morrow, Sophie Osotimehin, Tiago Ribeiro, Matthew Shapiro, Rishi Sharma, and seminar participants at various institutions for helpful suggestions. We are especially grateful to Matias Cattaneo for extensive input that greatly improved the paper. Di Giovanni thanks the Marie Curie International Incoming Fellowship FP7-PEOPLE-2013-IIF for financial support under Grant Agreement 622959. This research is supported by a public grant overseen by the French National Research Agency (ANR) as part of the "Investissements d'Avenir" program (Idex Grant Agreement ANR-11-IDEX-0003-02/Labex ECODEC ANR-11-LABEX-0047). All remaining errors are our own.
} 
aggregates. However, there is currently little empirical evidence on the role of individual firms and firm-to-firm linkages in aggregate fluctuations.

This paper constructs a novel data base covering the universe of French firms' domestic sales and destination-specific exports for the period 1990-2007, and uses it to provide a forensic account of the contribution of individual firms to aggregate fluctuations. To guide the empirical exercise, we set up a simple multisector model of heterogeneous firms in the spirit of Melitz (2003) and Eaton, Kortum, and Kramarz (2011). The model implies that the growth rate of sales of an individual firm to a single destination market can be decomposed additively into a macroeconomic shock (defined as the component common to all firms), a sectoral shock (defined as the component common to all firms in a particular sector), and a firm-level shock.

Relative to standard empirical assessments of the role of sectoral or firmspecific shocks, a novel aspect of our approach is that it accounts explicitly for the sector- and firm-level participation in export markets. When firms sell to multiple, imperfectly correlated markets, total firm sales do not admit an exact decomposition into macroeconomic, sectoral, and firm-specific shocks, whereas sales to an individual destination do. Thus, in our analysis macroeconomic, sectoral, and firm-specific shocks are defined for each destination market. The heterogeneity across markets also allows us to distinguish the firm-specific shocks affecting a firm's sales to all markets it serves from shocks particular to individual markets.

We compute macroeconomic, sectoral, and firm-specific shocks using data on the annual firm-destination sales growth rates. The firm-specific component accounts for the overwhelming majority (98.7\%) of the variation in sales growth rates across firms. ${ }^{2}$ In addition, about half of the variation in the firmspecific component is explained by variation in that component across destinations, which can be interpreted as destination-specific demand shocks in our conceptual framework.

We extract the time series of the macroeconomic, sectoral, and firm-specific shocks for each destination served by each firm. We use these realizations of shocks to assess whether microeconomic shocks contribute significantly to aggregate volatility, and if yes, through which channels. We derive a decomposition of aggregate volatility in the economy into the contributions of macroeconomic/sectoral and firm-specific shocks, and quantify the importance of the latter for aggregate volatility.

Our main finding is that the firm-specific components contribute substantially to aggregate fluctuations. The standard deviation of the firm-specific shocks' contribution to aggregate sales growth amounts to $80 \%$ of the standard deviation of aggregate sales growth in the whole economy and to $69 \%$

\footnotetext{
${ }^{2}$ This number is the share of the variance in the firm-destination growth rates that is not accounted for by the macro and sectoral components. Using the same metric, Haltiwanger (1997) and Castro, Clementi, and Lee (2013) find that idiosyncratic shocks account for more than $90 \%$ of the variation in firm growth rates in the U.S. Census' Longitudinal Research Database.
} 
in the manufacturing sector. This contribution is similar in magnitude to the combined effect of all sectoral and macroeconomic shocks. The standard deviation of the sectoral and macroeconomic shocks' contribution to aggregate sales growth is $53 \%$ of the standard deviation of aggregate sales growth for the overall economy and $64 \%$ for the manufacturing sector. ${ }^{3}$ To investigate whether exports differ systematically from domestic sales, we then carry out the aggregate volatility decomposition for domestic and export sales separately. ${ }^{4}$ The firm-specific component contributes more to the volatility of exports than that of overall sales both in the economy as a whole and in the manufacturing sector, where exporting is more prevalent. Nonetheless, firm-specific shocks contribute substantially to the volatility of aggregate domestic sales as well.

The overall contribution of firm-specific shocks to aggregate volatility can be decomposed additively into terms that capture two proximate explanations for why firm-specific shocks matter: (i) a weighted sum of all the variances of firm-specific shocks and (ii) a weighted sum of all the covariances between the firm-specific shocks. We refer to the first as the direct effect, since this is the aggregate variance that would obtain directly from shocks to individual firms and would be there even in the complete absence of interconnectedness between the firms. Gabaix (2011) shows that firm-specific idiosyncratic shocks do not average out because of the presence of very large firms. The second term collects cross-firm covariances and can thus be thought of as arising at least in part from interconnectedness between firms (sector-level versions of this argument are explored in Horvath (1998, 2000), Dupor (1999), Shea (2002), Conley and Dupor (2003), Acemoglu et al. (2012), among others). ${ }^{5}$ We refer to this as the linkages effect. Though both channels matter quantitatively, the majority of the contribution of firm-specific shocks to the aggregate variance is accounted for by the linkages term-the covariances of the firm-specific components of the sales growth rates.

We then exploit cross-sectoral heterogeneity to provide further evidence on the direct and linkages mechanisms. Gabaix (2011) shows that the direct effect of shocks to individual firms on aggregate fluctuations will be more pronounced the larger is the Herfindahl index of firm sales-a common measure of concentration. Confirming this result, firm-specific shocks in more concentrated industries, such as transport, petroleum, and motor vehicles, contribute

\footnotetext{
${ }^{3}$ These numbers add up to more than 1 because they have been converted to standard deviations. Since the aggregate variance is additive in the firm-specific and macro-sectoral variance components, the aggregate standard deviation is smaller than the sum of the standard deviations of the components.

${ }^{4}$ The analysis of the export subsample is motivated by two well known facts: (i) aggregate exports are more volatile than gross domestic product (GDP) and (ii) the largest firms tend to be exporters. Canals, Gabaix, Vilarrubia, and Weinstein (2007) show that international trade is very granular, both at the firm- and sector-destination level.

${ }^{5}$ Note that in this literature, the structural shocks are uncorrelated but generate positive covariances in firm sales.
} 
more to aggregate volatility than firm-specific shocks in less concentrated sectors such as metal products or publishing. We also compare the covariances of the firm-specific shocks aggregated to the sector level to a measure of sectoral linkages taken from the input-output tables. ${ }^{6}$ Sectors with stronger inputoutput linkages tend to exhibit significantly greater correlation of firm-specific shocks. We thus find direct corroboration in the data for the mechanisms behind both the direct and the linkages effects.

The results are robust in a number of dimensions. First and foremost, we continue to find a large contribution of firm-specific shocks to aggregate fluctuations when we allow for heterogeneous responses of firm sales growth to common shocks. In the baseline model, all firms have the same elasticity of sales with respect to the macroeconomic and sectoral shocks. While our framework shares this feature with the large majority of quantitative models in both macroeconomics and international trade, it is important to check whether the results are driven by this feature. In an alternative approach, we thus allow for the impact of sector-destination shocks on the growth rate of sales to vary by a wide variety of firm characteristics, such as size, age, access to capital markets, research and development (R\&D) intensity, or export orientation. As additional checks, we also implement the model under several alternative definitions of the sales growth rates, accounting for local geographical area effects, different levels of sectoral disaggregation, and using multi-year growth rates instead of yearly ones. The results are robust to all of these alternative implementations.

Our paper draws on, and contributes to, three key themes in macroeconomics. The first is the quest to understand how aggregate fluctuations can arise from microeconomic sources. This literature dates back to Long and Plosser (1983) and has traditionally focused on shocks at the sectoral level (see, e.g., Jovanovic (1987), Stockman (1988), Carvalho and Gabaix (2013), among many others). The second theme is that input-output linkages are the key mechanism through which microeconomic shocks propagate and lead to aggregate fluctuations. Once again, this literature has predominantly focused on sector-level linkages (see, e.g., Horvath (1998, 2000), Dupor (1999), Shea (2002), Conley and Dupor (2003), Foerster, Sarte, and Watson (2011), Acemoglu et al. (2012)). ${ }^{7}$

The third theme is that studying firm- and plant-level behavior is essential for understanding aggregate fluctuations. For instance, evidence on large gross employment flows at the micro level has stimulated a line of research

\footnotetext{
${ }^{6}$ Ideally, we would relate the covariance of firm-specific shocks to a measure of linkages at the firm level. However, currently firm-to-firm input-output tables do not exist for France, and thus we must look for these relationships at the sector level.

${ }^{7}$ Important exceptions are Cohen and Frazzini (2008), Hertzel, Li, Officer, and Rodgers (2008), and Kelly and Lustig (2013), who relate the supplier relationships among U.S. listed firms to movements in their stock prices and sales volatility.
} 
into their aggregate implications (Davis and Haltiwanger (1992), Davis, Haltiwanger, and Schuh (1996), Caballero, Engel, and Haltiwanger (1997), Davis, Faberman, and Haltiwanger (2006)). Similarly, plant-level investment is dominated by infrequent and large spikes, and an active literature has explored whether these micro-level patterns affect the behavior of aggregate investment (see, among many others, Doms and Dunne (1998), Cooper, Haltiwanger, and Power (1999), Cooper and Haltiwanger (2006), Gourio and Kashyap (2007)). Also closely related are studies of firm-level volatility (see, e.g., Comín and Philippon (2005), Davis, Haltiwanger, Jarmin, and Miranda (2007), Castro, Clementi, and Lee (2013), Thesmar and Thoenig (2011), Moscarini and PostelVinay (2012), Yoonsoo and Mukoyama (2012)). These research agendas have tended to emphasize that studying micro behavior is important as a way to learn what are the salient frictions in the economy. By and large, this literature has not pursued the idea that shocks to individual firms can impact aggregate fluctuations. A landmark recent exception is Gabaix (2011), who shows how idiosyncratic shocks to firms can lead to aggregate fluctuations in an economy dominated by very large firms and provides empirical evidence for this phenomenon using U.S. data. di Giovanni and Levchenko (2012a) extend this model to a multicountry framework and argue that it can help rationalize cross-country differences in the magnitude of aggregate fluctuations.

In line with the first two themes, our analysis emphasizes the role of both individual shocks and input-output linkages. In line with the third theme, but in contrast to the earlier literature, we shift the focus from sectors to firms. Our paper is the first to provide comprehensive empirical evidence on firms' contribution to aggregate fluctuations using the population of firms in a particular country. In addition, we incorporate the international dimension and show that it is important for a reliable computation of shocks. Finally, our data enable us to examine in detail the mechanisms behind the role of individual firms in generating aggregate volatility.

The rest of the paper is organized as follows. Section 2 presents a simple heterogeneous firms model and derives a theoretically founded decomposition of firm sales growth in each market into firm-specific, sector-level, and macroeconomic components. The section then derives a procedure to compute each component's contribution to aggregate volatility. Section 3 describes the data. Section 4 presents the main results. Section 5 concludes. The Supplemental Material (di Giovanni, Levchenko, and Mejean (2014)) contains the Appendixes and data and programs.

\section{CONCEPTUAL FRAMEWORK}

Total aggregate sales $X_{t}$ by all French firms to all destinations in year $t$ are by definition given by $X_{t} \equiv \sum_{f, n \in I_{t}} x_{f n t}$, where $x_{f n t}$ is defined as the sales of firm $f$ 
to market $n$ in year $t$, and $I_{t}$ is the set of firms $f$ and destinations $n$ being served at $t$. Thus, the unit of observation is a firm-destination pair, rather than a firm. ${ }^{8}$ The growth rate of aggregate sales is then defined simply as $\gamma_{A t}=X_{t} / X_{t-1}-1$, where we assume that $X_{t-1}$ and $X_{t}$ are the aggregate sales of all firms that exist both at $t-1$ and $t$, that is, we restrict attention to the intensive margin of aggregate sales growth. The choice to focus on the intensive margin is motivated in part by the difficulty of measuring the extensive margin reliably. Appendix A develops a complete decomposition of the total sales growth into extensive and intensive margins, and presents the results for the relative contributions of the extensive (as best as we can measure it) and intensive margins to aggregate volatility. The main result is that the large majority of the variance of aggregate sales is accounted for by the volatility of the intensive margin, with the extensive margin playing only a minor role. ${ }^{9}$ Section 4.4 .2 demonstrates the robustness of the results to an alternative definition of firm sales growth rates that treats entries and exits symmetrically with other sales. ${ }^{10}$

\subsection{A Motivating Model of Firm Sales Growth}

To motivate the decomposition of the growth of firm sales in a given year into (i) firm-destination and (ii) sector and country components, we set up a multisector heterogeneous firms model in the spirit of Melitz (2003) and Eaton, Kortum, and Kramarz (2011). While the model is largely illustrative and we will not use its full structure for estimation purposes, it serves to illustrate three main points. First, the sales decomposition adopted in our paper follows naturally from the workhorse heterogeneous firms model used in the literature. Second, the decomposition works only when applied to firm sales to an individual destination, rather than total (domestic plus export) sales. This result motivates our approach of extracting macro, sectoral, and idiosyncratic components for each individual destination market. And third, the model provides a simple and natural economic interpretation of the shocks as combinations of the demand and cost shocks that affect (sets of) firm-destinations.

There is a large number of countries indexed by $n$ and $J$ sectors indexed by $j$. In country $n$, consumer within-period utility is Cobb-Douglas in the sec-

\footnotetext{
${ }^{8}$ That is, suppose that there are two firms $f \in\{$ Renault, Peugeot $\}$ and two markets, $n \in$ \{France, Germany $\}$, and both firms sell to both markets. Then $I_{t}=\{\{$ Renault, France $\}$, $\left\{\right.$ Renault, Germany\}, $\{$ Peugeot, France $\},\{$ Peugeot, Germany\} $\}$ and $X_{t}$ is simply a summation over the sales of each firm to each destination.

${ }^{9}$ These results are consistent with other work on the role of the extensive margin in short-run aggregate fluctuations in the French economy. For instance, Osotimehin (2013) finds that entry and exit contribute little to the year-on-year variability of French aggregate productivity.

${ }^{10}$ Recent work focuses on the importance of the extensive adjustment at the product level, potentially within a firm (e.g., Bernard, Redding, and Schott (2010), Bilbiie, Ghironi, and Melitz (2012)), whereas in our data, it is only possible to measure the extensive margin at the firm level.
} 
tors $1, \ldots, J$,

$$
U_{n t}=\prod_{j=1}^{J}\left(C_{j n t}\right)^{\varphi_{j n t}},
$$

where $C_{j n t}$ is consumption of sector $j$ in country $n$ at time $t$, and $\varphi_{j n t}$ is a timevarying demand shock for sector $j$ in country $n$ (as in Eaton, Kortum, Neiman, and Romalis (2011)). The Cobb-Douglas functional form for the utility function leads to the well known property that expenditure on sector $j$ is a fraction $\varphi_{j n t}$ of the total expenditure in the economy, $Y_{j n t}=\varphi_{j n t} Y_{n t}$, where $Y_{n t}$ is aggregate expenditure in country $n$ at time $t$ and $Y_{j n t}$ is the expenditure in sector $j$.

Each sector $j$ is a constant elasticity of substitution (CES) aggregate of $\Omega_{j n t}$ varieties available in country $n$ at time $t$, indexed by $f$,

$$
C_{j n t}=\left[\sum_{f \in \Omega_{j n t}}\left(\omega_{f n t}\right)^{1 / \theta} C_{f n t}^{(\theta-1) / \theta}\right]^{\theta /(\theta-1)},
$$

where $\omega_{f n t}$ is a time-varying demand shock for variety $f$ in market $n$.

Every firm belongs to exactly one sector. Sector $j$ in the producing country ( $d=$ France) is populated by $I_{j d t}$ firms. Each of these firms sells a unique variety and, thus, has some market power. Firms also differ in productivity, with firm $f$ characterized by a time-varying unit input requirement $a_{f d t}$. Firm $f$ takes $a_{f d t}$ input bundles to produce one unit of its good in period $t$. The input bundle in sector $j$ in country $d$ and period $t$ has a cost $c_{j d t}$. Note that it can vary by sector, but not across firms within a sector. This input bundle can include, for instance, labor costs and the cost of capital. It is well known that these firms will price at a constant markup over their marginal cost, and conditional on selling to market $n$, sales by a French firm $f$ (i.e., residing in country $d$ ) to market $n$ in period $t$ are given by

$$
x_{f n t}=\omega_{f n t} \frac{\varphi_{j n t} Y_{n t}}{\left(P_{j n t}\right)^{1-\theta}}\left(\frac{\theta}{\theta-1} \kappa_{j n d} c_{j d t} a_{f d t}\right)^{1-\theta},
$$

where $P_{j n t}$ is the price level in sector $j$ in country $n$ at time $t$ and $\kappa_{j n d}$ is the iceberg cost of selling from France to country $n$ in sector $j$. This equation assumes that (i) $\kappa_{\text {jnd }}$ is sector-specific, but does not vary over time (though that assumption can easily be relaxed, in which case the time variation in $\kappa_{j n d}$ will be absorbed in the sector-destination shock), and (ii) the cost bundle $c_{j d t}$ and the marginal cost $a_{f d t}$ may vary over time, but are not destination-specific.

Sales to a single destination are then multiplicative in the macroeconomic, sectoral, and firm-specific components. The sales growth rate $\gamma_{f n t}$ of firm $f$ in sector $j$ to market $n$ between time $t-1$ and time $t$ is approximated by a $\log$ difference,

$$
\gamma_{f n t}=\tilde{\delta}_{n t}+\tilde{\delta}_{j n t}+\varepsilon_{f n t},
$$


where $\tilde{\delta}_{n t}=\Delta \log Y_{n t}$ is the aggregate ("macroeconomic") shock to the destination demand (to France if $n=d), \tilde{\delta}_{j n t}=\Delta \log \varphi_{j n t}+(1-\theta)\left(\Delta \log c_{j d t}-\right.$ $\Delta \log P_{j n t}$ ) captures the sectoral (country $n$-specific) demand and cost shock, and $\varepsilon_{f n t}=\Delta \log \omega_{f n t}+(1-\theta) \Delta \log a_{f d t}$ is the firm-specific demand and cost shock. Equation (4) characterizes firm sales growth to the domestic French market and to every foreign market.

While the theoretical framework distinguishes between macroeconomic shocks that are common to all firms selling goods in the same market and sectoral shocks in that market, in practice the macroeconomic shock and all of the sectoral shocks cannot be computed separately without further restrictions on the form they can take. However, since we are ultimately interested in the firm-specific component and its contribution to aggregate fluctuations, this does not pose a problem. In what follows, we work with the simpler model

$$
\gamma_{f n t}=\delta_{j n t}+\varepsilon_{f n t}
$$

that decomposes sales growth into a firm-specific shock $\varepsilon_{f n t}$ and a sectordestination shock $\delta_{j n t}=\tilde{\delta}_{n t}+\tilde{\delta}_{j n t}$ encompassing the macroeconomic and sectoral shocks.

\subsection{Econometric Model}

The analysis below views the $\varepsilon_{f n t}$ 's and $\delta_{j n t}$ 's as a set of stochastic processes that are (potentially) both cross-sectionally and serially correlated. Our ultimate goal is to assess the impact of firm-specific shocks $\varepsilon_{f n t}$ on aggregate fluctuations. Under the log-difference approximation (5) to the growth rates of individual firms, the growth rate $\gamma_{A t}$ of aggregate sales between $t-1$ and $t$ can be written as

$$
\gamma_{A t}=\sum_{j, n} w_{j n t-1} \delta_{j n t}+\sum_{f, n} w_{f n t-1} \varepsilon_{f n t},
$$

where $w_{j n t-1}$ is the share of sector $j$ 's sales to market $n$ in total sales of French firms to all sectors and destinations, and $w_{f n t-1}$ is the share of firm $f$ 's sales to destination $n$ in total sales. Unfortunately, working with equation (6) directly to produce a variance decomposition is impractical because time-varying weights $w_{f n t-1}$ make the stochastic process (6) difficult to analyze.

Instead, we work with a closely related set of stochastic processes:

$$
\gamma_{A t \mid \tau}=\sum_{j, n} w_{j n \tau-1} \delta_{j n t}+\sum_{f, n} w_{f n \tau-1} \varepsilon_{f n t} .
$$

For a given $\tau, \gamma_{A t \mid \tau}$ is a stochastic process in which weights $w_{f n \tau-1}$ are fixed over time at their $\tau-1$ values and are combined with shocks from period $t$. 
Naturally, when $\tau=t$, the "synthetic" aggregate growth rate $\gamma_{A t \mid \tau}$ coincides with the actual aggregate growth rate $\gamma_{A t}$. The last term in (7), $\sum_{f, n} w_{f n \tau-1} \varepsilon_{f n t}$, is none other than Gabaix's (2011) "granular residual," with the key difference that we build it with the $\varepsilon_{f n t}$ 's of all firms in the economy, rather than the top 100 firms as in Gabaix (2011).

Denote by $\sigma_{A \tau}^{2}$ the variance of $\gamma_{A t \mid \tau} \cdot{ }^{11}$ Using (7), it can be written as

$$
\sigma_{A \tau}^{2}=\sigma_{J N \tau}^{2}+\sigma_{F \tau}^{2}+\mathrm{COV}_{\tau},
$$

where

$$
\begin{aligned}
& \sigma_{J N \tau}^{2}=\operatorname{Var}\left(\sum_{j, n} w_{j n \tau-1} \delta_{j n t}\right) \quad(\text { sector-destination volatility), } \\
& \sigma_{F \tau}^{2}=\operatorname{Var}\left(\sum_{f, n} w_{f n \tau-1} \varepsilon_{f n t}\right) \quad \text { (firm-specific volatility), } \\
& \operatorname{COV}_{\tau}=\operatorname{Cov}\left(\sum_{j, n} w_{j n \tau-1} \delta_{j t}, \sum_{f, n} w_{f n \tau-1} \varepsilon_{f n t}\right)
\end{aligned}
$$

(covariance of the shocks from different levels of aggregation).

The intuition for this procedure can be conveyed as follows. Since $\delta_{j n t}$ and $\varepsilon_{f n t}$ are random variables, the growth rate of aggregate sales at time $\tau$ in (7) is itself a random variable and its variance is given by (8). The estimate of $\sigma_{A \tau}^{2}$ for a particular year can thus be thought of as the estimated variance of the aggregate growth rate in year $\tau$. We are interested in exploiting the form of $\gamma_{A t \mid \tau}$ to decompose the overall variance of $\gamma_{A t \mid \tau}$ into firm-specific and other components, so as to assess the importance of firm-specific shocks for aggregate fluctuations.

In practice, we will be reporting estimates of $\sigma_{A \tau}^{2}$ and its components for each $\tau=1991, \ldots, 2007$, as well as their averages over this period. The approach of constructing aggregate variances under weights that are fixed period-by-period follows Carvalho and Gabaix (2013), who perform a related exercise using sectoral data.

\subsection{Estimation}

The main goal of the paper is to provide estimates for $\sigma_{A \tau}^{2}, \sigma_{J N \tau}^{2}$, and $\sigma_{F \tau}^{2}$. Using sales data $\gamma_{f n t}$, the macro-sectoral shock $\delta_{j n t}$ is computed as the average growth rate of sales of all firms selling in sector $j$ to market $n$. The firm-specific shock $\varepsilon_{f n t}$ is computed as the deviation of $\gamma_{f n t}$ from $\delta_{j n t}$. This approach to iden-

\footnotetext{
${ }^{11}$ Appendix B presents further discussion of how our $\sigma_{A \tau}^{2}$ 's relate to the variances of actual aggregate growth rate $\gamma_{A t}$ and its components.
} 
tifying firm-specific shocks is adopted by Gabaix (2011) and Castro, Clementi, and Lee (2013), and follows in the tradition of Stockman (1988), who applied it at the sector level.

Our estimator for $\sigma_{F \tau}^{2}$ is simply the sample variance of the $T$ realizations of the scalar-valued time series $\sum_{f, n} w_{f n \tau-1} \varepsilon_{f n t}$. Similarly, the estimators for $\sigma_{A \tau}^{2}$ and $\sigma_{J N \tau}^{2}$ are the sample variances of the realizations of $\gamma_{A t \mid \tau}$ and $\sum_{j, n} w_{j n t-1} \delta_{j n t}$, respectively. Our sample consists of the realizations of the stochastic processes $\delta_{j n t}$ and $\varepsilon_{f n t}$ for $T=17$ years. Our framework allows for both cross-sectional and time dependence in the data-generating process. That is, $\varepsilon_{f n t}$ for firm $f$ can be correlated with another firm's $\varepsilon_{g n t}$ as well as with its own past values. However, we do assume that the stochastic process for $\varepsilon_{f n t}$ and $\delta_{j n t}$ is jointly stationary, that its degree of time dependence is not too high, and that $\gamma_{A t \mid \tau}$ as well as its constituent parts have enough finite moments. Since both $\varepsilon_{f n t}$ and $\delta_{j n t}$ describe growth rates, stationarity and limited time dependence are plausible assumptions. In practice, in our sample the autocorrelation in the series for $\gamma_{A t \mid \tau}$ and its constituent parts is minimal. Appendix C states these conditions precisely, and proves the consistency and asymptotic normality of the estimators as $T$ grows large. The appendix also gives formulas for the analytical standard errors of these estimators that we use below to construct confidence intervals. For robustness, we also report confidence intervals based on bootstrapping procedures.

We follow the convention in the literature and use the standard deviation as our measure of volatility. Therefore, when discussing contributions to aggregate volatility, we will present the results in terms of relative standard deviations, such as $\sigma_{F \tau} / \sigma_{A \tau}$.

\subsection{Discussion}

The first term in (8) measures the volatility of sector-destination shocks, which affect all firms in a sector selling to a particular destination market. It can be expressed as $\sigma_{J N \tau}^{2}=\sum_{k, m} \sum_{j, n} w_{j n \tau-1} w_{k m \tau-1} \operatorname{Cov}\left(\delta_{j n t}, \delta_{k m t}\right)$, making it clear that it is driven by the volatility of the sector-destination shocks $\left(\operatorname{Var}\left(\delta_{j n t}\right)\right)$ and their covariance across countries and sectors $\left(\operatorname{Cov}\left(\delta_{j n t}, \delta_{k m t}\right)\right)$. Obviously, the importance of any country- or sector-specific shock in explaining aggregate volatility is increasing in the relative size of that market (measured by $w_{j n \tau-1}$ ). Thus, French shocks have a larger impact on aggregate volatility than shocks affecting French firms' sales to, say, Japan. Likewise, a country specializing in highly volatile sectors is likely to display larger aggregate fluctuations (Koren and Tenreyro (2007), di Giovanni and Levchenko (2012b)). In that sense, diversification of sales across markets and sectors helps reduce aggregate fluctuations. In the meantime, comovement across countries or sectors tends to amplify aggregate fluctuations. For instance, an increased synchronization of business cycles among Economic and Monetary Union (EMU) members might 
drive up French volatility. Cross-sector correlations, created for example by input-output linkages, will also increase aggregate volatility (see, e.g., di Giovanni and Levchenko (2010)).

The second term in (8), $\sigma_{F \tau}^{2}$, is the variance of the granular residual. It measures the contribution of firm-specific shocks to aggregate fluctuations. As in Gabaix (2011), the firm-specific contribution to aggregate volatility is likely to be larger, everything else equal, the more fat-tailed is the distribution of sales across firms. Furthermore, volatility also increases if the larger firms face more volatile shocks. Finally, a positive correlation of shocks across firms, for instance, driven by input-output linkages, will increase firms' contribution to aggregate fluctuations. Section 4.3 discusses in more detail the microeconomic underpinnings of $\sigma_{F \tau}^{2}$, both in theory and in our data.

The firm-specific shocks $\varepsilon_{f n t}$ need not be uncorrelated with each other as in Gabaix (2011). For example, these shocks may covary among firms if their activity is interconnected, say through input-output linkages (e.g., Foerster, Sarte, and Watson (2011), Acemoglu et al. (2012)) or other potential firm interactions. To illustrate this possibility, Appendix E presents a simple extension of the model that includes intermediate inputs specific to the firm. These intermediate linkages lead to positive comovement of firm-specific shocks through the propagation of productivity shocks from input providers to downstream firms. To assess the relevance of this channel, below we develop a decomposition of the firm-specific variance and covariance contributions to aggregate volatility, and provide evidence that industry structure and other proxies for linkages matter.

We have argued that from a theoretical perspective, it is important to compute shocks for each market separately. In our theoretical framework, the firm-specific shock $\varepsilon_{f n t}=\Delta \log \omega_{f n t}+(1-\theta) \Delta \log a_{f d t}$ contains a component common across all destination markets and a component that is destinationspecific. Thus, it can be further decomposed as

$$
\varepsilon_{f n t}=\varepsilon_{f t}^{1}+\varepsilon_{f n t}^{2},
$$

where $\varepsilon_{f t}^{1}$ is the firm-specific shock common to all destinations and $\varepsilon_{f n t}^{2}$ captures the destination-specific demand shock. Specifically, we compute $\varepsilon_{f t}^{1}$ as the time $t$ average of $\varepsilon_{f n t}$ for each firm that serves multiple destinations (including the domestic market). Note that this procedure does not allow us to separate demand shocks from cost shocks cleanly, because $\varepsilon_{f t}^{1}$ captures not only the productivity shock $(1-\theta) \Delta \log a_{f d t}$, but also other firm-level shocks that are common across destinations, for instance, common taste shocks. Nonetheless, we can get a sense of the relative importance of the firmwide versus destinationspecific shocks by computing the share of variation in $\varepsilon_{f n t}$ that is absorbed by $\varepsilon_{f t}^{1}$. 


\section{DATA AND SUMMARY STATISTICS}

The analysis employs firm-level data containing the universe of domestic and export sales of French firms over the 1990-2007 period. Even though the time dimension is somewhat limited, we are still able to pick up cycles of the French economy, including the 1992-1993 and 2000-2001 recessions, and the acceleration of growth at the end of the nineties. The firm-level information is sourced from two rich data sets provided to us by the French administration. The first data set, obtained from the fiscal administration, contains balance-sheet information collected from the firms' tax forms, most importantly total firm sales. The second data set is the firm-level export data from the French customs authorities. This data base gives the (free on board) value of each French firm's exports to each of its foreign destination markets in a given fiscal year.

Appendix D contains a detailed description of the data. Our final data set covers 1,577,039 firms undertaking activities in 52 NAF (Nomenclature d'Activités Française) sectors, representing around 30\% of industrial and service firms but more than $90 \%$ of aggregate sales. Of those firms, 208,596 belong to the manufacturing sector (22 NAF industries), which accounts for around $30 \%$ of aggregate sales. In our sample, $18 \%$ of all firms (and $42 \%$ of manufacturing firms) export at some point in time. The total sales and export sales in this sample of firms mimic aggregate activity quite well: the growth rate of total sales tracks the growth rate of GDP (Figure 1), while the growth of total export sales moves with the growth of country exports over time (Figure 2).

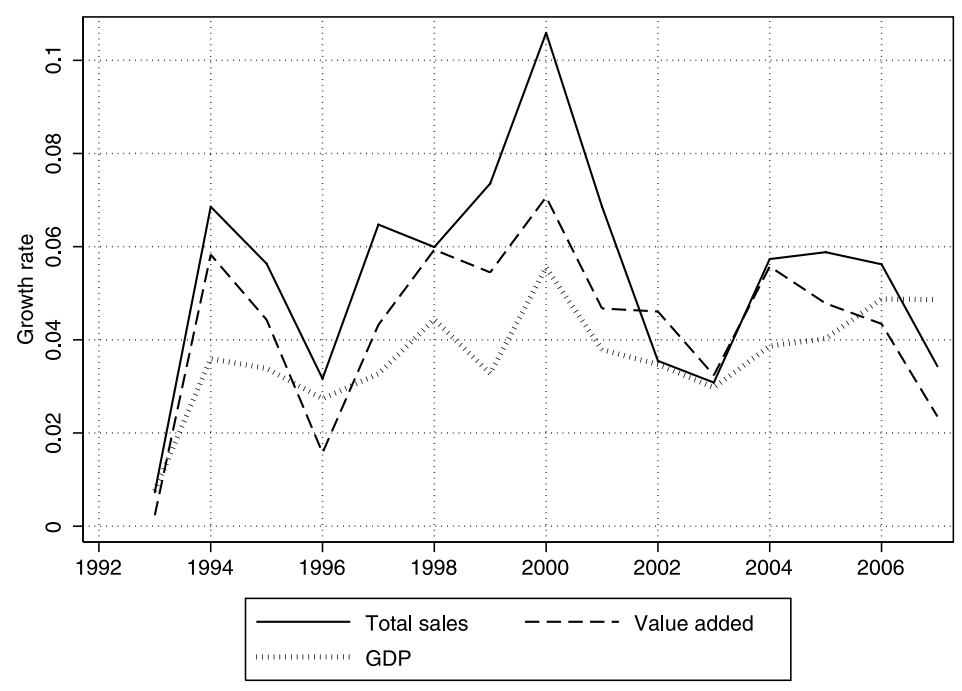

FIGURE 1.-Growth of aggregate sales, aggregate value added, and GDP. This figure presents the time series of the growth rates of total sales and before-tax value added in our data and GDP sourced from the International Monetary Fund (IMF) International Financial Statistics. 


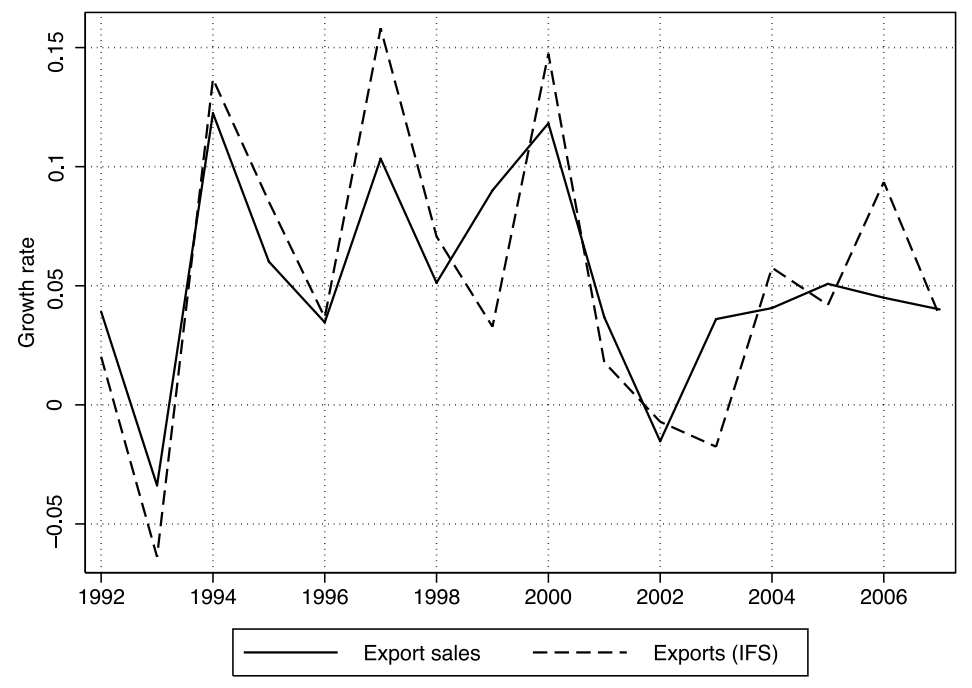

FIGURE 2.-Growth of aggregate exports. This figure presents the time series of the growth rates of total exports in our data and total French exports sourced from the IMF International Financial Statistics.

Table I presents summary statistics for firm-level growth rates for the whole economy and the manufacturing sector. The average growth rate of aggregate sales, 0.0369 for the whole economy and 0.0290 for manufacturing, is lower than the (unweighted) average growth rate of individual firm-destinations, which is 0.0465 for the whole economy and 0.0537 for manufacturing. This is to be expected, as smaller firms tend to grow faster than larger firms, conditional on survival. The average firm-destination has a standard deviation of sales growth of 0.23 in the whole economy and 0.28 in manufacturing. The table also reports averages of firm sales volatility by quintile. Smaller firms are more volatile than large ones. The very top firms, however, are even less volatile than the top quintile firms. While the top $20 \%$ of firm-destinations by size have an average standard deviation of sales growth of almost $20 \%$, the top 100 firm-destinations have an average standard deviation of $13 \%$ and the top 10 firms slightly lower still. Finally, the table also reports the square root of the firm-destination Herfindahl index of sales shares as well as the square root of the overall firm sales Herfindahl index. The Herfindahl indices have an order of magnitude consistent with what has been conjectured by Gabaix (2011) and show that the economy is "granular": shocks to the large firms have the potential to lead to aggregate fluctuations. All in all, the patterns for the manufacturing sector are quite similar to the whole economy.

Table II presents the average standard deviations of firm-destination growth rates across sectors, along with the shares of each sector in total sales. The raw volatility of sales growth varies across sectors, with the standard deviation rang- 
TABLE I

SUMMARY STATISTICS ${ }^{\mathrm{a}}$

\begin{tabular}{lcc}
\hline \hline & Whole Economy & Manufacturing Sector \\
\hline Average aggregate growth rate & 0.0369 & 0.0290 \\
Mean of individual growth rates & 0.0465 & 0.0537 \\
Standard deviation of sales growth rate & & \\
Average & 0.2342 & 0.2829 \\
0-20 size percentile & 0.3011 & 0.3550 \\
21-40 size percentile & 0.2425 & 0.3252 \\
41-60 size percentile & 0.2163 & 0.2654 \\
61-80 size percentile & 0.2043 & 0.2409 \\
81-100 size percentile & 0.2069 & 0.2278 \\
Top 100 & 0.1319 & 0.1816 \\
Top 10 & 0.1269 & 0.1364 \\
Average $\sqrt{\operatorname{Herf}(f, n)}$ & 0.0301 & 0.0447 \\
Average $\sqrt{\operatorname{Herf}(f)}$ & 0.0332 & 0.0592 \\
\hline
\end{tabular}

${ }^{a}$ This table presents the summary statistics for the whole economy and manufacturing firms over 1991-2007. $\operatorname{Herf}(f, n)$ is the Herfindahl index of the firm-destination sales shares. Herf $(f)$ is the Herfindahl index of the total firm sales shares.

ing from a low of 0.1489 (Health and social work) to a high of 0.3248 (Coke, refined petroleum, and nuclear fuel), and a cross-sectoral mean standard deviation of 0.2593 . The wholesale and retail trade sector has by far the highest share in aggregate sales, at nearly $37 \%$ of the total. While the standard deviation of sales growth, at 0.2188 , is quite typical of the rest of the economy, clearly wholesale and retail trade is quite special in other ways. To establish the robustness of the results, all of the analysis below is carried out both on the whole economy and on the manufacturing sector.

The analysis in the paper uses the growth rates of firm-destination sales. Other related work focuses on measures of firm productivity such as value added per worker (e.g., Gabaix (2011), Castro, Clementi, and Lee (2013)) or total factor productivity (TFP) (Carvalho and Gabaix (2013)), or employment (e.g., Moscarini and Postel-Vinay (2012)). Unfortunately, neither employment nor value added per worker data can be broken down into destinations-it is of course impossible to know which workers in the firm are producing for exports and which for domestic sales-whereas we show above that to carry out our analysis, the destination-by-destination breakdown is essential. This is the reason we use sales growth in the baseline analysis. As a robustness check, Section 4.2 presents the results for value added growth, under the (nontrivial) assumption that a firm's value added has the same breakdown across markets as its sales do. We cannot compute the firms' TFP process for the additional reason that we do not have firm-specific input and output deflators (Klette and Griliches (1996), among others, discuss the serious shortcomings of firm-level 
TABLE II

Firm-LeVel Volatility by SECTOR ${ }^{\mathrm{a}}$

\begin{tabular}{|c|c|c|c|c|c|c|c|}
\hline NAF & Sector & St. Dev. & Share & NAF & Sector & St. Dev. & Share \\
\hline$\overline{01-05}$ & Agriculture, forestry, and fishing & 0.2389 & 0.0049 & 35 & Other transport equipment & 0.3232 & 0.0113 \\
\hline $10-14$ & Mining and quarrying & 0.2533 & 0.0037 & $36-37$ & Manufacturing n.e.c. & 0.2853 & 0.0096 \\
\hline $15-16$ & Food and tobacco & 0.2340 & 0.0635 & $40-41$ & Electricity, gas, and water supply & 0.2103 & 0.0292 \\
\hline 17-19 & Textile, wearing apparel, and leather & 0.3118 & 0.0150 & 45 & Construction & 0.2314 & 0.0495 \\
\hline 20 & Wood products & 0.2606 & 0.0049 & 50 & Wholesale and retail trade & 0.2188 & 0.3689 \\
\hline $21-22$ & Paper products, publishing & 0.2558 & 0.0235 & 55 & Hotels and restaurants & 0.1614 & 0.0141 \\
\hline 23 & Coke, refined petroleum, and nuclear fuel & 0.3255 & 0.0241 & $60-63$ & Transport & 0.2033 & 0.0399 \\
\hline 24 & Chemical industry & 0.3193 & 0.0421 & 64 & Post and telecommunications & 0.2425 & 0.0226 \\
\hline 25 & Rubber and plastics & 0.3066 & 0.0145 & 70 & Real estate activities & 0.2102 & 0.0235 \\
\hline 26 & Mineral products & 0.2689 & 0.0114 & 71 & Rental without operator & 0.2158 & 0.0070 \\
\hline 27 & Basic metals & 0.3189 & 0.0129 & 72 & Computer services & 0.2695 & 0.0114 \\
\hline 28 & Metal products & 0.2715 & 0.0207 & 73 & Research and development & 0.2915 & 0.0015 \\
\hline 29 & Machinery and equipment & 0.3122 & 0.0203 & 74 & Other business services & 0.2384 & 0.0578 \\
\hline 30 & Office machinery & 0.3241 & 0.0051 & 75 & Public administration & 0.1734 & 0.0003 \\
\hline 31 & Electrical equipment & 0.3096 & 0.0111 & 80 & Education & 0.2283 & 0.0014 \\
\hline 32 & Radio, TV, and communication & 0.3161 & 0.0100 & 85 & Health and social work & 0.1490 & 0.0069 \\
\hline 33 & Medical and optical instruments & 0.3017 & 0.0079 & $90-93$ & Personal services & 0.1986 & 0.0164 \\
\hline 34 & Motor vehicles & 0.2950 & 0.0332 & & & & \\
\hline
\end{tabular}

aThis table presents the standard deviations of firm-destination growth rates broken down by sector over 1991-2007. "Share" is the share of the sector in total sales. The manufacturing sector covers NAF sectors 15-37. "N.e.c." stands for "not elsewhere classified." 
TFP estimation that does not employ firm-specific price data). We can also calculate the means and standard deviations of employment and value added per worker growth rates, and compare them to firm-destination sales growth rates. It turns out that these series have very similar first and second moments. For the whole economy, employment growth is 0.0345 at the mean, with an average standard deviation of 0.2437 ; value added per worker growth is 0.0400 , with an average standard deviation of 0.2586 . All of these are quite close to the corresponding numbers for sales growth in Table I. ${ }^{12}$

\section{EMPIRICAL RESULTS}

\subsection{Properties of Shocks}

Before assessing the impact of firm-specific shocks on aggregate volatility, we present the importance of the different components in explaining the variation in sales growth at the firm-destination level. The top panels of Table III and Table IV report the relative standard deviations of the firm-destination components and the sector-destination shocks for the whole economy and the manufacturing sector, respectively. The last column reports the correlation of each component with the actual firm sales growth. The bottom two panels report the same statistics for domestic and export firm sales.

It is clear that at the level of an individual firm-destination, variation in sales growth is dominated by the firm-specific component, rather than the sector-destination shocks. The standard deviation of the firm-specific component is nearly the same as the standard deviation of actual sales growth and the correlation is almost perfect. By contrast, the estimated sector-destination shocks are much less volatile and have much lower correlation with actual sales growth. These results are of course not surprising and confirm the conventional wisdom that most shocks hitting firms are firm-specific (Haltiwanger (1997), Castro, Clementi, and Lee (2013)). ${ }^{13}$ Examining the bottom two panels, it is clear that the importance of the firm-specific component is similar for both domestic and export sales.

It has been less well understood whether the firm-specific shocks are mostly common to all destination markets served by the firm or mostly destinationspecific. Table $\mathrm{V}$ presents the results of extracting the common firm component from firm-destination effects as in equation (9), for both the whole econ-

\footnotetext{
${ }^{12}$ Average sales growth reported in the table is lower than the sum of average value added per worker growth and average employment growth. Value added is defined as total sales minus input purchases (taking into account changes in the value of input inventories) plus changes in inventories plus subsidies minus taxes. Thus, sales would grow slower than value added if these other categories had slower growth rates than value added. This appears to be the case in our data, reconciling the seeming discrepancy.

${ }^{13} \mathrm{~A}$ variance decomposition of the firm-level growth rates indicates that $98.7 \%$ is accounted for by the firm-specific component for the whole economy ( $98.2 \%$ for the manufacturing sector).
} 
TABLE III

SUMmaRY STATISTICS AND CORRELATIONS OF ACTUAL FIRM-DESTINATION-LEVEL GROWTH AND FIRM-SPECIFIC VERSUS SECTOR-DESTINATION-SPECIFIC COMPONENTS:

WHOLE ECONOMY ${ }^{\mathrm{a}}$

\begin{tabular}{|c|c|c|c|c|}
\hline & $\begin{array}{l}\text { Obs. } \\
(1)\end{array}$ & $\begin{array}{l}\text { Mean } \\
\text { (2) }\end{array}$ & $\begin{array}{l}\text { St. Dev. } \\
\text { (3) }\end{array}$ & $\begin{array}{c}\text { Correlation } \\
\text { (4) }\end{array}$ \\
\hline \multicolumn{5}{|c|}{ A. Total Sales } \\
\hline Actual & $9,856,891$ & 0.0467 & 0.2601 & 1.0000 \\
\hline Firm-specific & $9,856,891$ & 0.0000 & 0.2584 & 0.9935 \\
\hline Sector-destination & 16,235 & 0.0762 & 0.1209 & 0.1140 \\
\hline \multicolumn{5}{|c|}{ B. Domestic Sales } \\
\hline Actual & $8,031,453$ & 0.0410 & 0.2266 & 1.0000 \\
\hline Firm-specific & $8,031,453$ & 0.0000 & 0.2255 & 0.9954 \\
\hline Sector-destination & 595 & 0.0453 & 0.0297 & 0.0957 \\
\hline \multicolumn{5}{|c|}{ C. Export Sales } \\
\hline Actual & $1,825,438$ & 0.0718 & 0.3723 & 1.0000 \\
\hline Firm-specific & $1,825,438$ & 0.0000 & 0.3697 & 0.9931 \\
\hline Sector-destination & 15,640 & 0.0774 & 0.1229 & 0.1171 \\
\hline
\end{tabular}

\footnotetext{
a "Actual" refers to $\gamma_{f n t}$, "Firm-specific" to $\varepsilon_{f n t}$, and "Sector-destination" to $\delta_{j n t}$ (equation (5)). Column (2) reports the average $\gamma_{f n t}, \varepsilon_{f n t}$, and $\delta_{j n t}$ in the sample of firm-destinations and years. Column (3) reports the average sample standard deviation of $\gamma_{f n t}, \varepsilon_{f n t}$, and $\delta_{j n t}$. Column (4) presents the correlation between $\gamma_{f n t}$ and $\gamma_{f n t}, \varepsilon_{f n t}$, and $\delta_{j n t}$.
}

\section{TABLE IV}

SUMMARY STATISTICS AND CORRELATIONS OF ACTUAL FIRM-DESTINATION-LEVEL GROWTH AND FIRM-SPECIFIC VERSUS SECTOR-DESTINATION-SPECIFIC COMPONENTS: MANUFACTURING SECTOR ${ }^{\mathrm{a}}$

\begin{tabular}{|c|c|c|c|c|}
\hline & $\begin{array}{l}\text { Obs. } \\
(1)\end{array}$ & $\begin{array}{l}\text { Mean } \\
(2)\end{array}$ & $\begin{array}{l}\text { St. Dev. } \\
\text { (3) }\end{array}$ & $\begin{array}{c}\text { Correlation } \\
\text { (4) }\end{array}$ \\
\hline \multicolumn{5}{|c|}{ A. Total Sales } \\
\hline Actual & $2,436,013$ & 0.0542 & 0.3038 & 1.0000 \\
\hline Firm-specific & $2,436,013$ & 0.0000 & 0.3011 & 0.9909 \\
\hline Sector-destination & 10,269 & 0.0727 & 0.0885 & 0.1342 \\
\hline \multicolumn{5}{|c|}{ B. Domestic Sales } \\
\hline Actual & $1,233,902$ & 0.0378 & 0.2233 & 1.0000 \\
\hline Firm-specific & $1,233,902$ & 0.0000 & 0.2214 & 0.9917 \\
\hline Sector-destination & 306 & 0.0416 & 0.0313 & 0.1285 \\
\hline \multicolumn{5}{|c|}{ C. Export Sales } \\
\hline Actual & $1,202,111$ & 0.0709 & 0.3679 & 1.0000 \\
\hline Firm-specific & $1,202,111$ & 0.0000 & 0.3652 & 0.9927 \\
\hline Sector-destination & 9,963 & 0.0737 & 0.0895 & 0.1207 \\
\hline
\end{tabular}

a "Actual" refers to $\gamma_{f n t}$, "Firm-specific" to $\varepsilon_{f n t}$, and "Sector-destination" to $\delta_{j n t}$. Column (2) reports the average $\gamma_{f n t}, \varepsilon_{f n t}$, and $\delta_{j n t}$ in the sample of firm-destinations and years. Column (3) reports the average sample standard deviation of $\gamma_{f n t}, \varepsilon_{f n t}$, and $\delta_{j n t}$. Column (4) presents the correlation between $\gamma_{f n t}$ and $\gamma_{f n t}, \varepsilon_{f n t}$, and $\delta_{j n t}$. 
TABLE V

SUMMARY STATISTICS AND CORRELATIONS OF FIRM-SPECIFIC GROWTH AND COMPONENTS ${ }^{\mathrm{a}}$

\begin{tabular}{|c|c|c|c|c|}
\hline & $\begin{array}{c}\text { Obs. } \\
(1)\end{array}$ & $\begin{array}{l}\text { Mean } \\
\text { (2) }\end{array}$ & $\begin{array}{l}\text { St. Dev. } \\
\text { (3) }\end{array}$ & $\begin{array}{c}\text { Correlation } \\
\text { (4) }\end{array}$ \\
\hline \multicolumn{5}{|c|}{ A. Whole Economy } \\
\hline Firm & $2,273,943$ & 0.0009 & 0.3450 & 1.0000 \\
\hline Firm-dest. & $2,273,943$ & 0.0000 & 0.3011 & 0.8728 \\
\hline Firm-com. & 479,101 & 0.0020 & 0.1949 & 0.4881 \\
\hline \multicolumn{5}{|c|}{ B. Manufacturing Sector } \\
\hline Firm & $1,448,234$ & -0.0003 & 0.3436 & 1.0000 \\
\hline Firm-dest. & $1,448,234$ & 0.0000 & 0.3052 & 0.8880 \\
\hline Firm-com. & 258,530 & 0.0007 & 0.1854 & 0.4598 \\
\hline
\end{tabular}

a"Firm" refers to $\varepsilon_{f n t}$, "Firm-dest." to $\varepsilon_{f n t}^{2}$, and "Firm-com." to $\varepsilon_{f t}^{1}$ (equation (9)). This table presents the average growth rates and standard deviations of $\varepsilon_{f n t}, \varepsilon_{f n t}^{2}$, and $\varepsilon_{f t}^{1}$ in the sample, as well as the correlations between $\varepsilon_{f n t}$ and $\varepsilon_{f n t}, \varepsilon_{f n t}^{2}$, and $\varepsilon_{f t}^{1}$. The set of firm-destinations is restricted to firms that serve at least two markets.

omy and the manufacturing sector. ${ }^{14}$ Looking at the data through the lens of the model in Section 2, this decomposition is suggestive of whether supply or demand shocks are driving firms' sales growth. Since the firm's marginal cost of serving each market (modulo iceberg trade costs) is the same, productivity shocks will be part of the component of the firm-specific shock that is common to all destinations. In addition, the common component will also include the part of the taste shock $\omega_{f n t}$ for firm $f$ that is common across locations $n$. The destination-specific component of the firm shock is then interpreted as a demand shock idiosyncratic to a particular location.

Results are similar for the two sets of firms. For the economy as a whole, the destination-specific component has a higher relative standard deviation than the common factor $(0.30$ vs. 0.19$)$. It is also more correlated with the total estimated firm-specific component (correlation coefficient of 0.87 compared to 0.49 for the common component). For the manufacturing sector, the relative standard deviation of the destination-specific shock is 0.31 , whereas that of the common shocks is 0.19. Similarly, the correlation with the overall firmspecific component is higher for the destination-specific component than for the common component ( 0.89 vs. 0.46$)$. We conclude from this exercise that destination-specific shocks at the firm level are more important than the shocks common to all destinations. ${ }^{15}$

\footnotetext{
${ }^{14}$ Note that this decomposition can only be done for firms that serve at least two markets. Therefore, the number of firm-destination and firm-common observations will be smaller than the total number of firm-specific shocks in Tables III and IV.

${ }^{15}$ This result is consistent with the findings of Eaton, Kortum, and Kramarz (2011), who estimate a structural trade model on French export data and find that a firm-destination specific
} 


\subsection{The Aggregate Impact of Firm-Specific Shocks}

The fact that most of the variation in the growth rate of sales is accounted for by firm-specific shocks does not mean that firm-specific shocks manifest themselves in aggregate fluctuations. To assess the importance of the different types of shocks for the aggregate, we must take into account the distribution of firm size by decomposing the aggregate sales volatility as in Section 2.2.

Figure 3 and Table VI report the main results of the paper. Figure 3 depicts the estimates of $\sigma_{A \tau}$ and its main components: firm-specific $\left(\sigma_{F \tau}\right)$ and sector-destination $\left(\sigma_{J N \tau}\right)$ for the whole economy (panel A) and the manufacturing sector (panel B). The figure also displays two kinds of $95 \%$ confidence intervals: analytical and bootstrapped. Table VI reports the averages of our estimates of $\sigma_{A \tau}, \sigma_{J N \tau}$, and $\sigma_{F \tau}$, as well as their ratios, over the sample period. The results for the whole economy are in the first two columns, and for the manufacturing sector in the next two columns.

Not surprisingly, the firm-destination component matters much less for the aggregate sales volatility than for the volatility of individual firm sales. However, its importance is nonnegligible: for the whole economy the relative standard deviation of the firm-specific component of aggregate sales is 0.8 relative to that of actual sales volatility. In fact, our results show that the firm-specific component is more important for aggregate fluctuations than the contribution of sector-destination shocks, which has a relative standard deviation of 0.53 .

The standard deviation of the firm-specific component comoves with the standard deviation of aggregate sales over time, whereas the standard deviation of sector-destination shocks is nearly constant over time. Recalling how the different components are calculated from (8), note that the time variation in sales' share (at the firm and sector-destination levels) will drive the time variation in the different volatility measures. These shares do not change dramatically at the sector-country level. More interestingly, the firm-specific shocks increase in importance over time. For the whole economy, the relative standard deviation of the firm-specific to total sales is about 0.5 at the beginning of the sample and about 0.85 at the end. These results are a first glimpse of the importance of large firms and firm linkages on aggregate fluctuations. We discuss further what drives these findings in Section 4.3.

The contributions of firm-specific and macro-sector shocks are both statistically significant throughout the sample. In spite of computing the sample variance on a time series of only 17 observations for each $\sigma_{F \tau}$ and $\sigma_{J N \tau}$, we always have enough power to reject the null that the contribution of $\sigma_{F \tau}$ and $\sigma_{J N \tau}$ is nil. The analytical standard errors are computed as detailed in Appendix C. These standard errors may not capture the full extent of estimation uncertainty in

shock has to be added for the model to fit the data. This suggests that firm-specific shocks common across destinations are not sufficient for explaining aggregate exports. 
A. Whole Economy

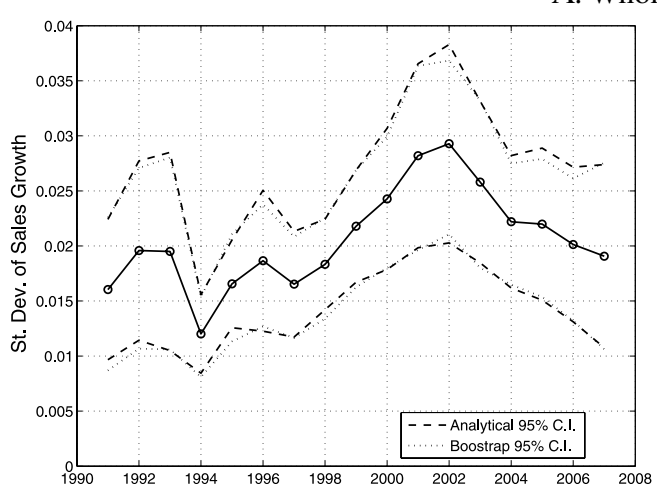

(a) Sales

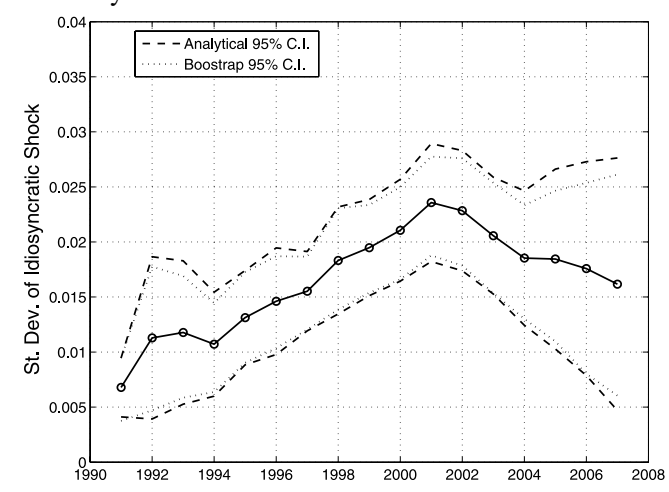

(b) Idiosyncratic

FIGURE 3.- Volatility of sales growth and its components. Notes: This figure presents the estimates of $\sigma_{A \tau}, \sigma_{F \tau}$, and $\sigma_{J N \tau}$ for the whole economy (panel A) and the manufacturing sector (panel B), along with both analytical and bootstrap $95 \%$ confidence intervals. 


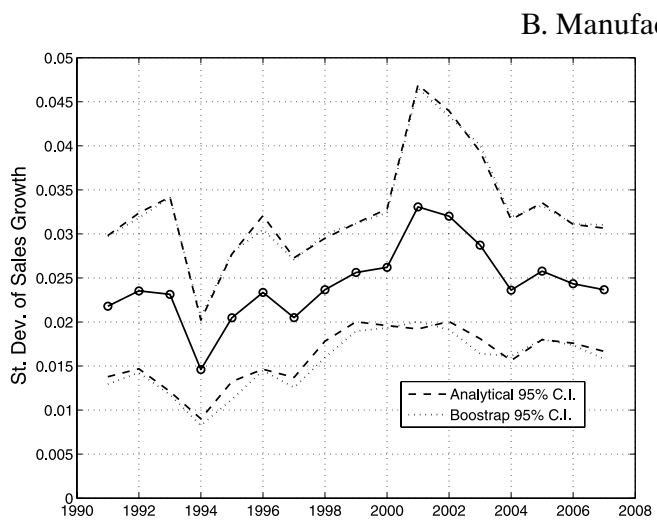

(d) Sales

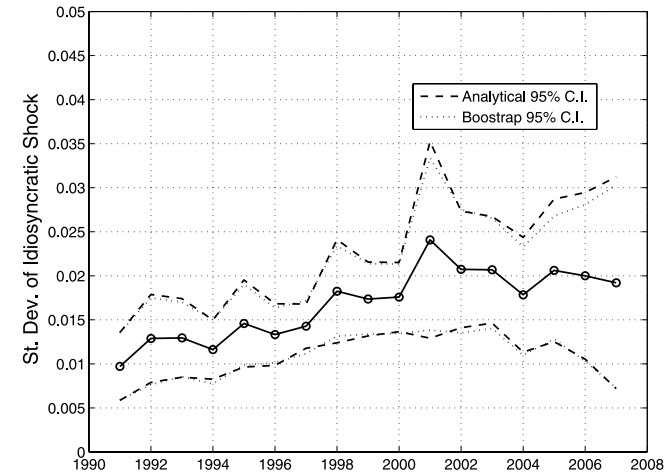

(e) Idiosyncratic

(f) Macroeconomic 
TABLE VI

The Aggregate IMpact of Firm-SPeCific Shocks on AgGregate Volatility: WHOLE ECONOMY AND MANUFACTURING SECTOR ${ }^{\mathrm{a}}$

\begin{tabular}{|c|c|c|c|c|}
\hline & \multicolumn{2}{|c|}{ Whole Economy } & \multicolumn{2}{|c|}{ Manufacturing Sector } \\
\hline & $\begin{array}{l}\text { St. Dev. } \\
\text { (1) }\end{array}$ & $\begin{array}{c}\text { Relative SD } \\
\text { (2) }\end{array}$ & $\begin{array}{l}\text { St. Dev. } \\
\text { (3) }\end{array}$ & $\begin{array}{c}\text { Relative SD } \\
\text { (4) }\end{array}$ \\
\hline \multicolumn{5}{|c|}{ A. Total Sales } \\
\hline Actual & 0.0206 & 1.0000 & 0.0244 & 1.0000 \\
\hline Firm-specific & 0.0165 & 0.8010 & 0.0168 & 0.6885 \\
\hline Sector-destination & 0.0109 & 0.5291 & 0.0157 & 0.6434 \\
\hline \multicolumn{5}{|c|}{ B. Domestic Sales } \\
\hline Actual & 0.0196 & 1.0000 & 0.0231 & 1.0000 \\
\hline Firm-specific & 0.0154 & 0.7857 & 0.0151 & 0.6537 \\
\hline Sector-destination & 0.0112 & 0.5714 & 0.0167 & 0.7229 \\
\hline \multicolumn{5}{|c|}{ C. Export Sales } \\
\hline Actual & 0.0361 & 1.0000 & 0.0374 & 1.0000 \\
\hline Firm-specific & 0.0304 & 0.8421 & 0.0287 & 0.7674 \\
\hline Sector-destination & 0.0129 & 0.3573 & 0.0153 & 0.4091 \\
\hline \multicolumn{5}{|c|}{ D. Value Added } \\
\hline Actual & 0.0210 & 1.0000 & 0.0215 & 1.0000 \\
\hline Firm-specific & 0.0190 & 0.9048 & 0.0184 & 0.8558 \\
\hline Sector-destination & 0.0107 & 0.5095 & 0.0123 & 0.5721 \\
\hline
\end{tabular}

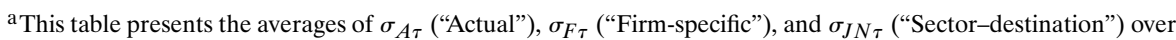
the sample period $-\frac{1}{T} \sum_{\tau=1991}^{2007} \sigma_{A \tau}, \frac{1}{T} \sum_{\tau=1991}^{2007} \sigma_{F \tau}, \frac{1}{T} \sum_{\tau=1991}^{2007} \sigma_{J N \tau}$-and in relative terms with respect to the actual- $\frac{1}{T} \sum_{\tau=1991}^{2007} \frac{\sigma_{F t}}{\sigma_{A \tau}}, \frac{1}{T} \sum_{\tau=1991}^{2007} \frac{\sigma_{J N t}}{\sigma_{A \tau}}$.
}

such a small sample. To explore robustness of the results further, we also use a block bootstrapping procedure in which, for each $\tau$, we sample 10,001 draws of 17 observations with replacement from the time series of $\gamma_{A t \mid \tau}, \sum_{j, n} w_{j n \tau-1} \delta_{j n t}$, and $\sum_{f, n} w_{f n \tau-1} \varepsilon_{f n t}$. The results are robust to using bootstrapped rather than analytical confidence intervals. ${ }^{16}$

The results for the manufacturing sector largely mimic those of the economy as a whole. The relative standard deviation of the firm-specific component of aggregate sales is 0.69 of actual sales volatility. In this set of firms, the firm-specific component is about as important for aggregate fluctuations as the sector-destination shocks, which have a relative standard deviation of 0.64. The contribution of firms to aggregate fluctuations also increases over time in the manufacturing sector, from 0.45 in 1991 to 0.81 in 2007.

${ }^{16} \mathrm{To}$ account for time dependence in the data, the bootstrap procedure samples (overlapping) blocks of one, two, and three observations. The figures report the confidence intervals under a block size of 1 , but differences are minimal if we instead use blocks of size 2 or 3 . 
Panels B and C of Table VI check the results on domestic and export sales separately. Both panels confirm the importance of firm-specific shocks for aggregate fluctuations. Moreover, export sales are dominated by firm-specific shocks, while the relative weights of firm-specific and sector-destination components as a driver of aggregate fluctuations are roughly equal for domestic sales. The greater relative importance of firm shocks for exports compared to domestic sales is exactly as expected given that exports are more granular than overall sales (Canals et al. (2007)).

Since GDP is measured in value added, GDP fluctuations correspond more closely to fluctuations in firm value added. We thus repeat the analysis using firm value added instead of gross sales. This exercise entails a nontrivial assumption. Namely, our framework makes it clear that for proper identification of shocks, we must use data on each destination separately. Since both exports and domestic sales are recorded in gross terms, when we use sales, this is noncontroversial: total firm sales are the sum of sales to each destination market served by the firm. Indeed, this is the reason that we work with sales throughout the paper.

However, for value added, we do not have the right data, because value added exports are not recorded. The data we have are (i) gross domestic sales and exports, and (ii) total firm value added. The assumption we make to move forward is that the breakdown of value added across markets follows the same proportions as total sales. Thus, to compute a firm's value added exports to Germany, we multiply total firm value added by the share of exports to Germany in the firm's total gross sales. In the absence of value added export data, this is the best we can do. It amounts to the restriction that the input usage inside the firm is identical for each destination of its output. For an advanced economy like France, this appears to be a reasonable assumption.

With that caveat, Table VI reports the results. Shocks to firm value added explain, if anything, more of the fluctuations in aggregate value added. The results are similar if we break up value added into the domestic and export components, and thus we do not report them to conserve space.

\subsection{Channels for Firms' Contribution to Aggregate Fluctuations}

Having established the substantial contribution of the firm-specific component to aggregate fluctuations, we next examine the estimates in greater detail so as to disentangle the economic mechanisms at work. Aggregate firm-specific volatility $\sigma_{F \tau}^{2}$ can be written as

$$
\sigma_{F \tau}^{2}=\operatorname{Var}\left(\sum_{f, n} w_{f n \tau-1} \varepsilon_{f n t}\right)=\sum_{g, m} \sum_{f, n} w_{g m \tau-1} w_{f n \tau-1} \operatorname{Cov}\left(\varepsilon_{g m t}, \varepsilon_{f n t}\right) .
$$


We decompose it following Carvalho and Gabaix (2013) into the contribution of individual variances and comovements between firms:

$$
\sigma_{F \tau}^{2}=\underbrace{\sum_{f, n} w_{f n \tau-1}^{2} \operatorname{Var}\left(\varepsilon_{f n t}\right)}_{\operatorname{DIRECT}_{\tau}}+\underbrace{\sum_{g \neq f, m \neq n} \sum_{f, n} w_{g m \tau-1} w_{f n \tau-1} \operatorname{Cov}\left(\varepsilon_{g m t}, \varepsilon_{f n t}\right)}_{\text {IINK }_{\tau}} .
$$

This decomposition emphasizes two potential proximate channels through which shocks to individual firms may lead to a large variance of the firm-specific component: (i) the variance of individual shocks, labelled DIRECT, and (ii) the covariance of shocks across firms, labelled LINK.

The first term in (10) captures the direct effect of shocks to firms on aggregate volatility, in the sense that it would obtain in the complete absence of firm-to-firm linkages. The predominant tradition in macroeconomics has been to assume that the DIRECT term is negligible due to the law of large numbers: when the distribution of firm size has finite variance, the impact of shocks to individual firms on aggregate volatility converges to zero at the rate $\sqrt{N}$, where $N$ is the number of firms (or, more precisely in our context, firm-destination sales) in the economy. However, recent literature in macroeconomics (most notably Gabaix (2011)) challenges this view by arguing that the observed firm size distribution is so fat-tailed that the conventional law of large numbers does not apply and shocks to individual (large) firms do, in fact, translate into aggregate fluctuations. ${ }^{17}$ The LINK component has also been ignored by most of the macroeconomics literature based on the argument that covariances between firms were, in fact, an artefact of firms being hit by common aggregate or sectoral shocks. This view has also been challenged in recent papers, such as Acemoglu et al. (2012) or Foerster, Sarte, and Watson (2011).

Figure 4 presents the decomposition graphically for the whole economy and the manufacturing sector. The LINK component explains the majority of total firm-specific volatility: $\sqrt{\mathrm{LINK}_{\tau}} / \sigma_{F \tau}$ is over $90 \%$ on average over the sample period for both the whole economy and the manufacturing sector. However, it is apparent from the figures that the DIRECT component is also nonnegligible. The ratio of $\sqrt{\text { DIRECT }_{\tau}}$ to $\sigma_{F \tau}$ is $26 \%$ on average over this period for the whole economy and $40 \%$ for the manufacturing sector.

\subsubsection{The Contribution of the Direct Effect}

As shown by Gabaix (2011), when the distribution of firm size is sufficiently fat-tailed (i.e., the economy is "granular"), idiosyncratic shocks to individual

\footnotetext{
${ }^{17}$ Gabaix (2011) shows that when the distribution of firm size follows a power law with an exponent close to 1 in absolute value-a distribution known as Zipf's law-aggregate volatility declines at the rate $\log N$ and idiosyncratic shocks will not cancel out in aggregate under a realistic number of firms in the U.S. economy. di Giovanni, Levchenko, and Rancière (2011) use the census of French firms to show that the firm size distribution in France does indeed follow Zipf's law.
} 


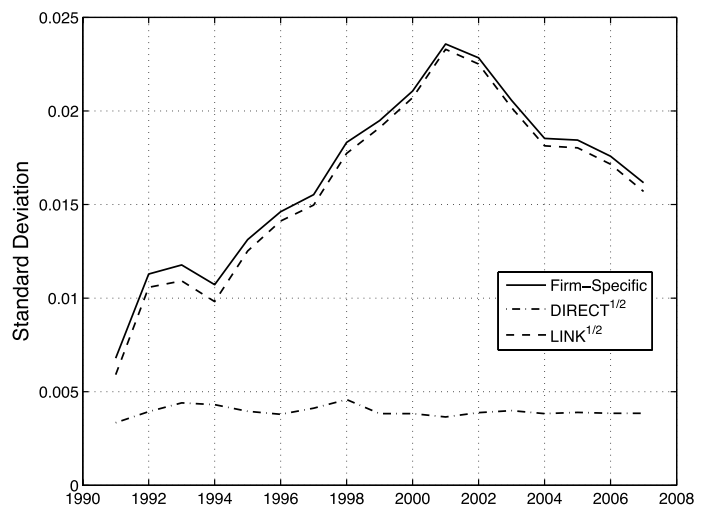

(a) Whole Economy

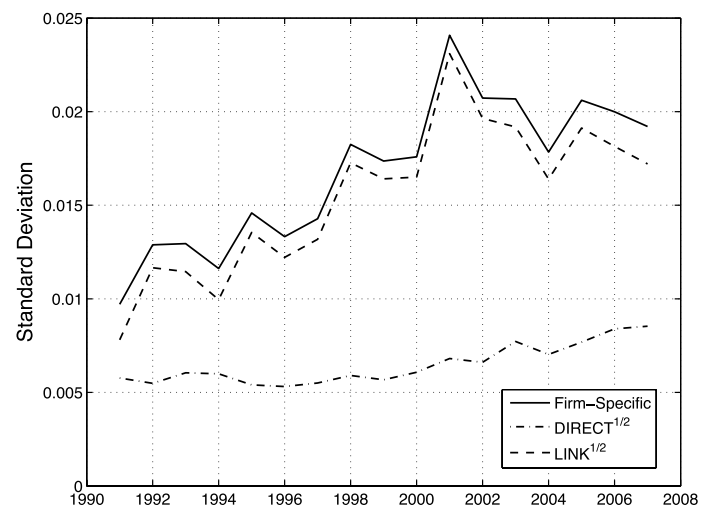

(b) Manufacturing Sector

FIGURE 4.-Contribution of individual volatilities and covariance terms to firm-specific fluctuations. Notes: This figure presents a decomposition of the firm-specific aggregate variance into two components that measure the contribution of firm-specific variances $\left(\sqrt{\text { DIRECT }_{\tau}}\right)$ and of covariances across firms $\left(\sqrt{\mathrm{LINK}_{\tau}}\right)$. The decomposition is based on equation (10).

firms do not wash out at the aggregate level, because the idiosyncratic shocks to large firms do not cancel out with shocks to smaller units. This idea can be discussed most easily in the simplest case when shocks are uncorrelated across firms (i.e., $\left.\operatorname{Cov}\left(\varepsilon_{g m t}, \varepsilon_{f n t}\right)=0 \forall(g, m) \neq(f, n)\right)$ and across markets within a firm $\left(\operatorname{Cov}\left(\varepsilon_{f m t}, \varepsilon_{f n t}\right)=0, m \neq n\right)$, and the variance of shocks is identical across firms $\left(\operatorname{Var}\left(\varepsilon_{f n t}\right)=\sigma^{2} \forall f, n\right)$. Under these assumptions, aggregate firm-specific volatility (10) is

$$
\sigma_{F \tau}^{2}=\sigma^{2} \sum_{f, n} w_{f n \tau-1}^{2}=\sigma^{2} \times \operatorname{Herf}_{\tau-1},
$$


where $\operatorname{Herf}_{\tau-1}=\sum_{f, n} w_{f n \tau-1}^{2}$ denotes the Herfindahl index. The more fat-tailed is the distribution of firm size, the larger will be the Herfindahl index and the greater will be the aggregate volatility generated by firm-specific shocks. In the opposite extreme case, if all firm-destination sales are instead symmetric in size $\left(w_{f n \tau-1}=1 / N_{\tau-1}\right.$, where $N_{\tau-1}$ is the number of firm-destination sales in the economy), $\sigma_{F \tau}=\sigma / \sqrt{N_{\tau-1}}$ and the contribution of firms to aggregate volatility decays rapidly with the number of firms in the economy.

The role of the firm size distribution emphasized by Gabaix (2011) can be illustrated using the following simple counterfactual. We calculate the DIRECT component under the assumption that all firms and markets are of equal weight (i.e., $\left.w_{f n \tau-1}=1 / N_{\tau-1} \forall f, n\right)$. When shocks are independent across firms, this "equal-weighted" aggregate variance is expected to be vanishingly small. Instead, the contribution of firms to aggregate volatility that takes into account the actual distribution of sales across firms is expected to be larger.

This is indeed what happens. For the whole economy, the $\sqrt{\text { DIRECT }}$ component implied by equal weights is 0.0003 , or 13 times smaller than the average $\sqrt{\text { DIRECT }}$ component, which is equal to 0.004 . For the manufacturing sector, the standard deviation implied by equal weights is 0.0008 , an order of magnitude smaller than the $\sqrt{\text { DIRECT }}$ component of 0.0065 . This comparison clearly shows that the firm size distribution does matter a great deal quantitatively for the contribution of individual firms' shocks to aggregate fluctuations.

Next, we exploit differences across sectors to evaluate the importance of the direct effect. To do so, we decompose the DIRECT component in equation (10) into sectors, where sector $j$ 's DIRECT component is defined as $\operatorname{DIRECT}_{j \tau} \equiv \sum_{(f, n) \in j} w_{f n \tau-1}^{2} \operatorname{Var}\left(\varepsilon_{f n t}\right)$, and $\operatorname{DIRECT}_{\tau}=\sum_{j=1}^{J} \operatorname{DIRECT}_{j \tau}$. Again, if $\operatorname{Var}\left(\varepsilon_{f n t}\right)=\sigma^{2} \forall f, n$, we would expect that more concentrated sectors would display larger volatilities. ${ }^{18}$ Figure 5 evaluates this prediction, by plotting (the square root of the) mean sectoral DIRECT ${ }_{j \tau}$ against the (square root of the) mean sectoral Herfindahl index for the whole economy and the manufacturing sector. In Figure 5, DIRECT ${ }_{j \tau}$ and the Herfindahl are computed with weights normalized by the size of each sector in aggregate sales. Otherwise, they would mechanically be proportional to the contribution of each sector to overall sales. The correlation is strongly positive: sectors with higher sales concentration contribute more to the total DIRECT component, which is consistent with granularity. The correlation is lower for the whole economy $(0.86)$ than for the manufacturing sector (0.93). The correlation is less than perfect because firm-level variances differ both across and within sectors. In the data, small firms tend to be more volatile on average (Table I). This heterogeneity

\footnotetext{
${ }^{18}$ The firm-specific volatilities do in fact vary by sector, to the same degree as the standard deviations of the raw growth rates in Table II-the correlation between the standard deviations of the actual growth rates and the firm-specific shocks is 0.996 across sectors.
} 


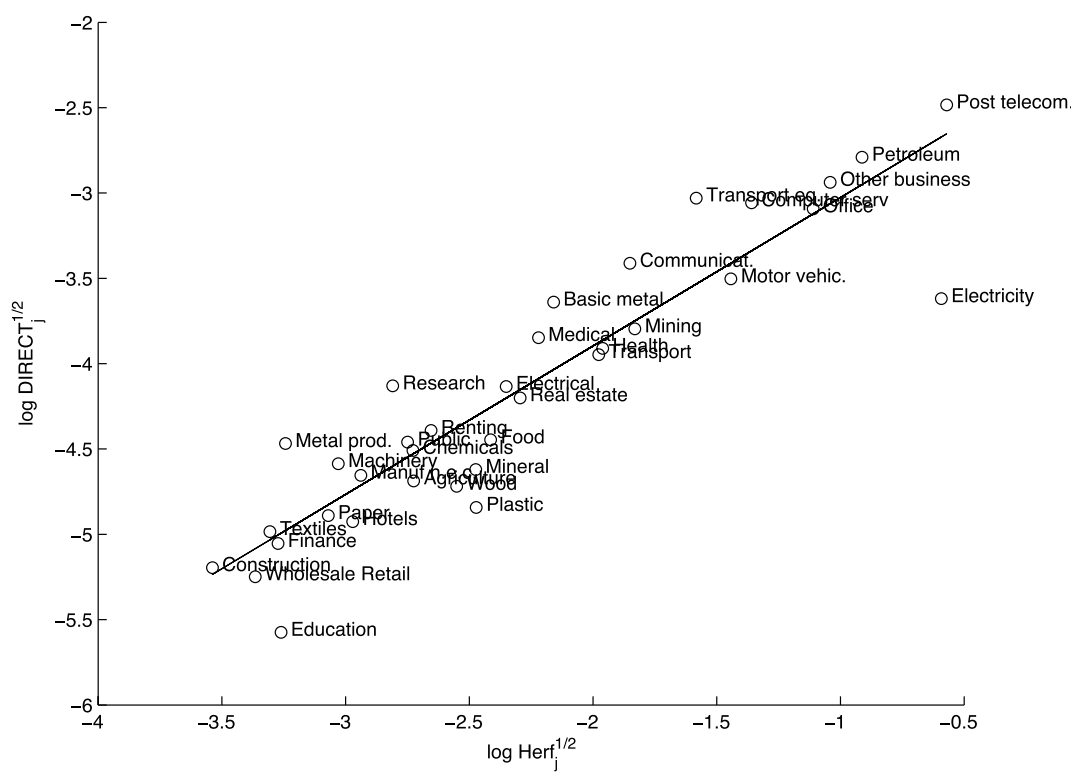

(a) Whole Economy

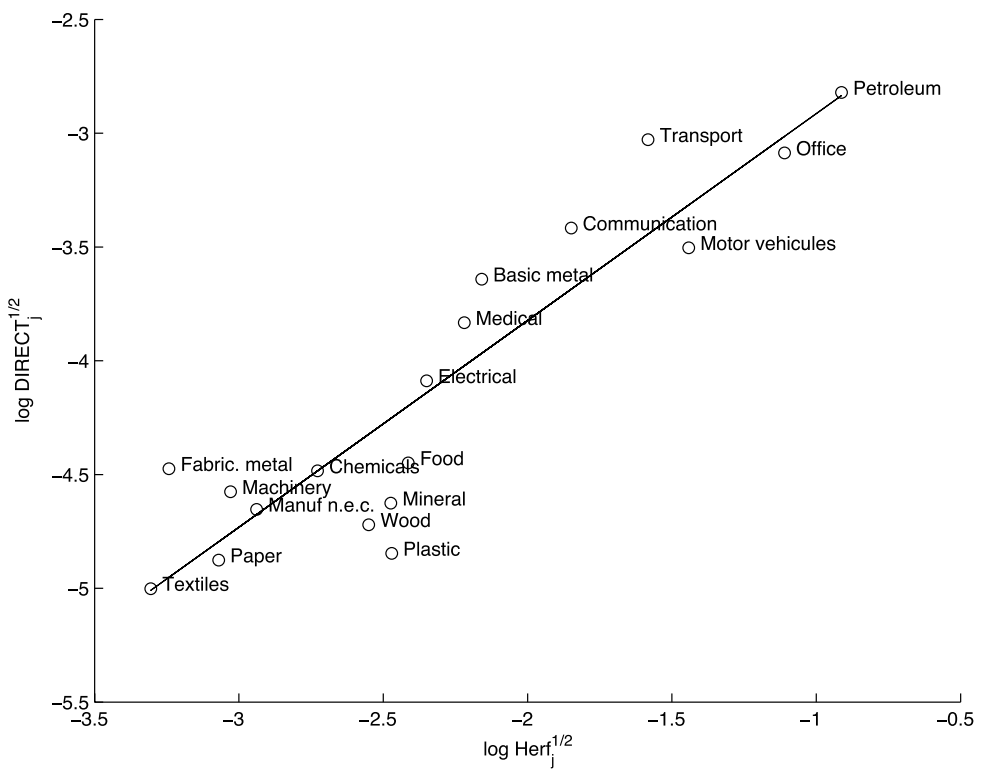

(b) Manufacturing Sector

FIGURE 5.-Firm-specific volatility aggregated at the sector level and the sectoral mean Herfindahl index. Notes: This figure plots the time average of the sectoral $\sqrt{\text { DIRECT }_{j \tau}}$ component against the square root of the sectoral mean Herfindahl index. The correlation between time average $\sqrt{\text { DIRECT }_{j \tau}}$ and $\sqrt{\text { Herf }_{j \tau}}$ is 0.86 for the whole economy and 0.93 for the manufacturing sector. 
in firm-level volatilities counteracts the impact of sales concentration, thus reducing the overall size of the DIRECT component relative to what would be expected in a purely "granular" world with identical variances across firms.

\subsubsection{The Contribution of Firm Linkages}

The second explanation for why firm shocks can drive aggregate fluctuations is inspired by the literature on the role of sectoral input-output linkages in aggregate fluctuations (Horvath (1998, 2000), Dupor (1999), Shea (2002), Conley and Dupor (2003), Gabaix (2011), Acemoglu et al. (2012)), and is captured by the covariance term LINK in (10). The idea is that idiosyncratic shocks do not wash out at the aggregate level because they propagate across firms or sectors through "interconnections." If firms in the economy are connected, say through input-output linkages, shocks affecting upstream firms propagate to downstream firms via adjustments in the price of inputs. This propagation mechanism amplifies the initial impact of structural shocks. Moreover, it generates positive covariances in the residual growth rate of sales for firms that are connected.

Note that simply observing positive covariances in the firm-specific components (gathered in the LINK term) is not conclusive evidence that inputoutput linkages are responsible for the comovement, as there may be other reasons for cross-sectional dependence between firms, such as local labor market interactions. While we cannot identify the precise share of the LINK term that is due to input-output linkages per se, we provide direct, if suggestive, evidence that input-output linkages are at least partly responsible for the positive LINK term.

Appendix E lays out a simple model of such firm-level interconnections. Firms produce with a constant marginal cost using labor and intermediate inputs bought from other firms in the economy. Input-output linkages create a positive covariance of sales growth rates for any two firms that are connected. For instance, take firms $f$ and $g$, and assume firm $g$ sells inputs to firm $f$. If the only source of shocks is productivity shocks to firm $g$, then the covariance between the sales growth rates of those two firms is

$$
\operatorname{Cov}\left(\varepsilon_{g m t}, \varepsilon_{f n t}\right)=(1-\theta)^{2}\left(1-\lambda_{f}\right) \rho_{f g} \operatorname{Var}\left(a_{g m t}\right),
$$

where $\theta$ is the elasticity of substitution, $\left(1-\lambda_{f}\right)$ is the share of intermediate goods in firm $f$ 's total costs, $\rho_{f g}$ is the share of those inputs that is sourced from firm $g$, and $\operatorname{Var}\left(a_{g m t}\right)$ is the volatility of firm $g$ 's productivity. The covariance is positive and increasing in the strength of the connection between $f$ and $g$, that is, in the share of inputs from $g$ used in $f$ 's production, $\left(1-\lambda_{f}\right) \rho_{f g}$. In this setup, the propagation goes from upstream to downstream firms through the price of inputs. In a more general setting, one can also expect shocks to 
propagate from downstream to upstream firms through the demand of intermediates. $^{19}$

Ideally, one would test the linkage hypothesis using firm-level measures of interconnections. Since information on firm-to-firm input linkages $\left(\rho_{f g}\right)$ is not available, we instead proxy for production networks using sector-level data and use the input-output (IO) tables for France compiled by the Organization for Economic Cooperation and Development (OECD). Assuming that the share of intermediates in total costs is homogeneous across firms within a sector (i.e., $\left.\lambda_{f}=\lambda_{i} \forall f \in i\right)$ and that all firms within a sector interact with the same input providers (i.e., $\rho_{f g}=\rho_{i j} \tilde{w}_{g / j} \forall f \in i, g \in j$, where $\tilde{w}_{g / j}$ is the share of firm $g$ in total sector $j$ intermediate input sales to $i$ ), the structure of sectoral IO matrices can be used to approximate the intensity of IO linkages between firms from each pair of sectors. The intensity of IO linkages between a pair of sectors can then be related to the magnitude of covariances between firms in those sectors. We expect the weighted sum of covariances to be higher for sector pairs that display stronger IO linkages. ${ }^{20}$

Figure 6 examines this hypothesis. We decompose the LINK component in equation (10) across sector pairs, where the LINK term specific to the pair $(i, j)$ is defined as $\operatorname{LINK}_{i j \tau} \equiv \sum_{(f, n) \in i} \sum_{(g, m) \in j} w_{f n \tau-1} w_{g m \tau-1} \operatorname{Cov}\left(\varepsilon_{f n t}, \varepsilon_{g m t}\right)$ and $\mathrm{LINK}_{\tau}=\sum_{i=1}^{J} \sum_{j=1 ; j \neq i}^{J} \mathrm{LINK}_{i j \tau}$. We then correlate the (square root of the) average $\mathrm{LINK}_{i j \tau}$ of a pair of sectors to the mean intensity of IO linkages between them. LINK $_{i j \tau}$ is normalized by the size of each sector to control for the mechanical impact of sector sizes on the magnitude of the aggregated covariance terms. The mean intensity of IO linkages is defined as $0.5 \times\left[\left(1-\lambda_{i}\right) \rho_{i j}+\left(1-\lambda_{j}\right) \rho_{j i}\right]$, where $\lambda_{i}$ is the share of value added in sector $i$ 's total output and $\rho_{i j}$ is the share of inputs from $j$ in sector $i$ 's spending on intermediates, both taken from the French IO tables for 1995. Input-output linkages are thus stronger if either one or both sectors intensively use intermediates from the other sector.

The correlation between the LINK term and the intensity of IO linkages is positive, both for the whole economy Figure 6(a) and the manufacturing sector Figure 6(b). ${ }^{21}$ The relationship is marginally more pronounced for the manu-

\footnotetext{
${ }^{19}$ This is ruled out in the setting of Appendix E as well as in the model of Acemoglu et al. (2012) because of the Cobb-Douglas assumption on the production function. More flexible specifications of technology would allow downstream firms' productivity shocks to propagate upstream to input providers.

${ }^{20}$ See Appendix E for details.

${ }^{21}$ Note that Figure 6 drops negative bilateral covariance terms as well as zero input-output linkages, since we are taking log transformations. Input-output linkages would not explain negative covariances according to the model. Such negative numbers should instead reflect substitution effects across competing firms. Likewise, our stylized model is unable to explain a strictly positive LINK term between firms in sectors that do not interact through IO linkages. Fortunately, observations with negative covariance terms and/or zero input-output linkages are rare in our data, representing less than $6 \%$ of the total possible sector pairs.
} 


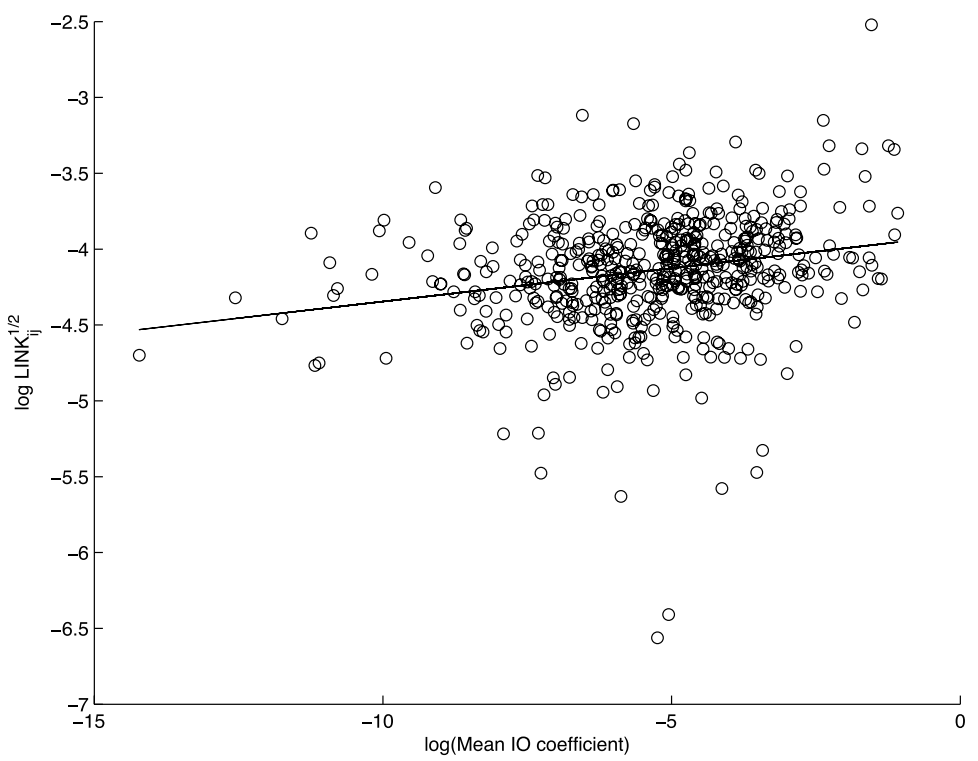

(a) Whole Economy

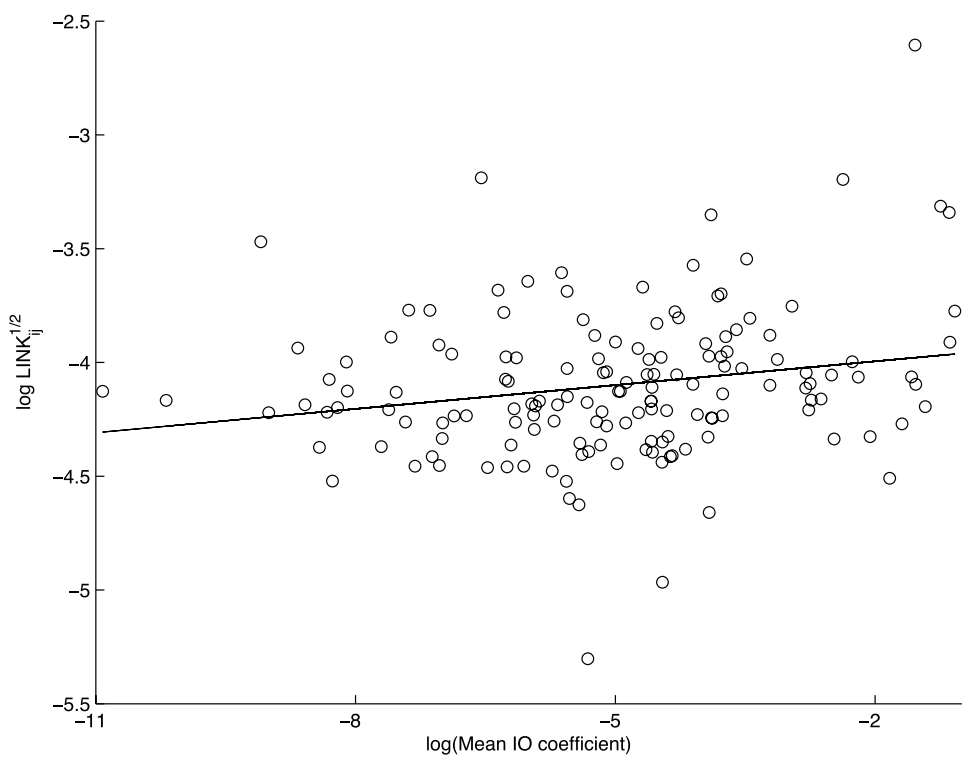

(b) Manufacturing Sector

FIGURE 6.-Covariances of firm-specific shocks across sectors and their input-output linkages. Notes: This figure plots the time average of the sector pair $\sqrt{\mathrm{LINK}_{i j \tau}}$ component against the mean IO linkage (share of intermediate inputs in total costs times the share of the upstream sector in intermediate consumption between sectors $i$ and $j$ ). The correlation between the time average $\sqrt{\mathrm{LINK}_{i j \tau}}$ and the IO linkages is 0.29 for the whole economy and 0.34 for the manufacturing sector. 
facturing sector, with a correlation coefficient of 0.34 compared to 0.29 for the whole economy. The results are direct empirical evidence that input-output linkages across firms are important in transmitting microeconomic shocks across the economy.

\subsection{Extensions and Robustness}

\subsubsection{Differences in Firm Sensitivity to Macro and Sectoral Shocks}

In the baseline model, the elasticity of firm sales with respect to aggregate and sectoral shocks is the same across firms. Our conceptual framework shares this feature with Dixit and Stiglitz (1977), Krugman (1980), Melitz (2003), and the enormous literature that followed in this tradition. However, it is possible that firms will systematically react differently to sector- and country-level shocks. In that case, the computed values of $\varepsilon_{f n t}$ will be combinations of firmspecific shocks and the heterogeneous responses to the aggregate and sectoral shocks. There are several theoretical channels that would deliver a heterogeneous response. One example is a model laid out in Appendix F, in which firms react heterogeneously to sector-destination shocks because of variable markups. di Giovanni and Levchenko (2012a) argue that the impact of this channel on aggregate volatility is small. However, as a robustness check, we carry out alternative estimations in which we instead impose the augmented model

$$
\gamma_{f n t}=\delta_{j n t}+\delta_{j n t} \times \mathrm{CHAR}_{f t}+\beta \mathrm{CHAR}_{f t}+\varepsilon_{f n t},
$$

where $\mathrm{CHAR}_{f t}$ is a particular observable firm characteristic. In this model, heterogeneity of firm responses to macroeconomic and sectoral shocks is thus systematically related to observable firm characteristics. We attempt a variety of different types of CHAR : $_{t}$ : measures of (i) firm size (log sales or sales quintile dummy), ${ }^{22}$ (ii) firm age (log years or dummy for whether the firm is less or more than 5 years old), ${ }^{23}$ (iii) R\&D intensity (dummy for whether R\&D expenses are higher than $1 \%$ of value added), ${ }^{24}$ (iv) patent intensity (dummy for whether patent expenses are more than $5 \%$ of value added), (v) export inten-

\footnotetext{
${ }^{22}$ Following the accepted practice in the literature, our preferred specification captures size differences using quintile dummies, since that allows for greater (nonparametric) flexibility in the functional form. See Fortin, Lemieux, and Firpo (2011) for an exhaustive survey on decomposition methods.

${ }^{23}$ Fort, Haltiwanger, Jarmin, and Miranda (2013) report that in the United States, young/small businesses are more sensitive to the cycle than older/larger businesses.

${ }^{24}$ Comín and Philippon (2005) report that in the United States, sectors with largest increases in $\mathrm{R} \& \mathrm{D}$ have become less correlated with the business cycle.
} 
TABLE VII

THE IMPACT OF FIRM-SPECIFIC SHOCKS ON AgGREGATE VOLATILITY: DIFFERING FIRM SENSITIVITY TO SECTORAL AND MACROECONOMIC SHOCKS ${ }^{\mathrm{a}}$

\begin{tabular}{|c|c|c|c|c|}
\hline & \multicolumn{2}{|c|}{ Whole Economy } & \multicolumn{2}{|c|}{ Manufacturing Sector } \\
\hline & $\begin{array}{l}\text { St. Dev. } \\
\text { (1) }\end{array}$ & $\begin{array}{l}\text { Relative SD } \\
\text { (2) }\end{array}$ & $\begin{array}{l}\text { St. Dev. } \\
\text { (3) }\end{array}$ & $\begin{array}{l}\text { Relative SD } \\
\text { (4) }\end{array}$ \\
\hline Actual & 0.0206 & 1.0000 & 0.0244 & 1.0000 \\
\hline \multicolumn{5}{|c|}{ Firm-Specific Component (Average $\sigma_{F \tau}$ ) } \\
\hline Differing sensitivity & & & & \\
\hline By size & 0.0169 & 0.8204 & 0.0172 & 0.7049 \\
\hline By age & 0.0122 & 0.5922 & 0.0133 & 0.5451 \\
\hline By R\&D intensity & 0.0164 & 0.7961 & 0.0167 & 0.6844 \\
\hline By patenting intensity & 0.0162 & 0.7864 & 0.0167 & 0.6844 \\
\hline By openness & 0.0166 & 0.8058 & 0.0167 & 0.6844 \\
\hline By debt & 0.0164 & 0.7961 & 0.0167 & 0.6844 \\
\hline By all of the above & 0.0134 & 0.6505 & 0.0123 & 0.5041 \\
\hline
\end{tabular}

${ }^{a}$ The row labelled "Actual" reports the average standard deviation of actual aggregate sales growth over 19912007: $\frac{1}{T} \sum_{\tau=1991}^{2007} \sigma_{A \tau}$. The rest of the table reports the average standard deviation of the firm-specific component, $\frac{1}{T} \sum_{\tau=1991}^{2007} \sigma_{F \tau}$, and its average value relative to the actual, $\frac{1}{T} \sum_{\tau=1991}^{2007} \frac{\sigma_{F \tau}}{\sigma_{A \tau}}$, under a series of augmented models (12) in which firms have heterogeneous sensitivity to sector-destination shocks. "Size" is the dummy for the firm's quintile in the sales distribution. "Age" is the dummy for whether the firm is more than 5 years old. "R\&D intensity" is a dummy for whether R\&D expenses are higher than $1 \%$ of value added. "Patent intensity" is a dummy for whether patent expenses are more than $5 \%$ of value added. "Openness" is the ratio of exports to total firm sales. "Debt" is the quintile dummy for the firm's debt to sales ratio.

sity (ratio of exports to total firm sales), ${ }^{25}$ and (vi) debt to sales ratio. ${ }^{26} \mathrm{We}$ also implement a model in which all of these characteristics are included together.

Table VII reports the results. Allowing firm sensitivity to aggregate and sectoral shocks to differ by firm size leaves the conclusions unchanged. The table reports the implementation in which firm size is captured by sales quintile dummies. The results are unaffected if we instead use a continuous measure of size, such as log sales, or use employment or total assets as measures of size. If we allow a firm's sensitivity to shocks to differ by firm age, the contribution of firm shocks to aggregate fluctuations falls somewhat. Nonetheless, the relative importance of firm-specific shocks for aggregate volatility, $\sigma_{F \tau} / \sigma_{A \tau}$, is still nearly 0.6 . The table reports the results of using a dummy for whether the firm is more than 5 years old. Using actual years of age instead leaves the results unchanged. Allowing sensitivity to differ by any of the other character-

\footnotetext{
${ }^{25}$ There is evidence that firms substitute domestic for foreign sales in response to demand shocks abroad (e.g., Blum, Claro, and Horstmann (2013)). Thus, it may be that exporters exhibit systematically different sensitivity to shocks in an individual market.

${ }^{26}$ There is evidence that access to capital markets affects firms' responses to aggregate shocks (Gertler and Gilchrist (1994), Kashyap, Lamont, and Stein (1994)).
} 
istics we consider-R\&D and patent intensity, overall export orientation, or debt structure-also leaves the results unchanged. While the table reports the results using the quintile dummies for the debt to total sales ratio of the firm, the results are unchanged if we instead use bond debt, bank debt, or ratio of bond to bank debt, each in both continuous and quintile dummy forms.

Finally, the last row of the table reports the results of allowing firm sensitivity to aggregate and sectoral shocks to depend on all of the above characteristics simultaneously. The importance of firm-specific shocks is somewhat lower than in the baseline, with $\sigma_{F \tau} / \sigma_{A \tau}$ equal to 0.65 for the whole economy and 0.5 for the manufacturing sector. Nonetheless, this contribution is still sizeable. We take this as evidence that our results are robust to allowing for firm-destination sales growth to react heterogeneously to macroeconomic and sectoral shocks.

\subsubsection{Entry and Exit}

The baseline analysis is carried out on the intensive margin, that is, sales growth rates for continuing firm-destinations. Appendix A presents an explicit decomposition of aggregate sales growth into extensive and intensive margins, and argues that the bulk of aggregate sales fluctuations is driven by the intensive margin. As an alternative approach, we report results for the growth rates adopted by Davis, Haltiwanger, and Schuh (1996) and the large literature that followed:

$$
\gamma_{f n t}^{\prime} \equiv \frac{x_{f n t}-x_{f n t-1}}{0.5\left(x_{f n t}+x_{f n t-1}\right)} .
$$

This growth rate, which we label DHS, has a number of attractive properties: it encompasses entries and exits (treating them in the same way as other observations), it ranges from -2 to 2 and thus limits the impact of outliers, and it lends itself to consistent aggregation. Under this definition of growth rates, the correct weights for aggregation are

$$
w_{f n t}^{\prime} \equiv \frac{\left(x_{f n t}+x_{f n t-1}\right)}{\sum_{f, n}\left(x_{f n t}+x_{f n t-1}\right)}
$$

and the aggregate growth rate of $x$ is

$$
\gamma_{A t}^{\prime} \equiv \frac{X_{t}-X_{t-1}}{0.5\left(X_{t}+X_{t-1}\right)}=\sum_{f, n} w_{f n t}^{\prime} \gamma_{f n t}^{\prime} .
$$

Note, however, that a firm growth defined this way does not admit a logdifference decomposition (4) into macro, sectoral, and firm-specific components, and thus the results using these growth rates should be interpreted as approximations. The results are presented in Table VIII, panel A. Using these 
TABLE VIII

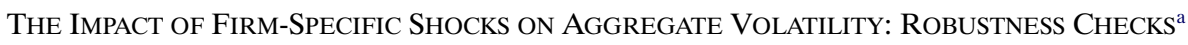

\begin{tabular}{|c|c|c|c|c|}
\hline & \multicolumn{2}{|c|}{ Whole Economy } & \multicolumn{2}{|c|}{ Manufacturing Sector } \\
\hline & $\begin{array}{l}\text { St. Dev. } \\
\text { (1) }\end{array}$ & $\begin{array}{c}\text { Relative SD } \\
\text { (2) }\end{array}$ & $\begin{array}{l}\text { St. Dev. } \\
\text { (3) }\end{array}$ & $\begin{array}{c}\text { Relative SD } \\
\text { (4) }\end{array}$ \\
\hline \multicolumn{5}{|c|}{ A. DHS Growth Rates } \\
\hline Actual & 0.1420 & 1.0000 & 0.1203 & 1.0000 \\
\hline Firm-specific & 0.1014 & 0.7141 & 0.0833 & 0.6924 \\
\hline \multicolumn{5}{|c|}{ B. Demeaned Growth Rates } \\
\hline Actual & 0.0206 & 1.0000 & 0.0244 & 1.0000 \\
\hline Firm-specific & 0.0128 & 0.6214 & 0.0152 & 0.6230 \\
\hline \multicolumn{5}{|c|}{ C. Additional Local Market Effects } \\
\hline Actual & 0.0206 & 1.0000 & 0.0244 & 1.0000 \\
\hline Firm-specific & 0.0165 & 0.8010 & 0.0164 & 0.6721 \\
\hline \multicolumn{5}{|c|}{ D. More Disaggregated Sectors } \\
\hline Actual & 0.0209 & 1.0000 & 0.0244 & 1.0000 \\
\hline Firm-specific & 0.0169 & 0.8086 & 0.0156 & 0.6393 \\
\hline \multicolumn{5}{|c|}{ E. Three-Year Growth Rates } \\
\hline Actual & 0.0290 & 1.0000 & 0.0323 & 1.0000 \\
\hline Firm-specific & 0.0266 & 0.9140 & 0.0269 & 0.8885 \\
\hline
\end{tabular}

aThe rows labelled "Actual" report the average standard deviation of actual aggregate sales growth over 19912007: $\frac{1}{T} \sum_{\tau=1991}^{2007} \sigma_{A \tau}$. The rows labelled "Firm-specific" report the average standard deviation of the firm-specific component, $\frac{1}{T} \sum_{\tau=1991}^{2007} \sigma_{F \tau}$, and its average value relative to the actual, $\frac{1}{T} \sum_{\tau=1991}^{2007} \frac{\sigma_{F \tau}}{\sigma_{A \tau}}$, under a series of alternative models. Panel A implements the model under the firm growth rate defined as in (13). Panel B reports the results under first demeaning firm sales growth by the firm-destination specific average growth rate. Panel C reports the results of augmenting the model to include location-specific shocks. Panel D reports the results under defining sectors according to the five-digit NAF level of disaggregation (about 700 sectors in the whole economy). Panel E uses the baseline model, but takes the average firm-destination growth rates over s periods: 1990-1993, 1994-1997, 1998-2001, 2002-2005. Means of standard deviations and relative standard deviations are presented.

growth rates changes the sample of firms and produces lower aggregate volatility, but the share of the firm-specific contribution to the aggregate volatility remains very similar to the baseline at $\sigma_{F \tau} / \sigma_{A \tau}$ of about 0.7 for both the whole economy and the manufacturing sector.

\subsubsection{Other Robustness Checks}

One may be concerned about how differential trend growth rates across firms (especially of different sizes) can affect the calculation of the firms' contribution to aggregate volatility. To check if this matters, we demean each firmdestination growth rate by the average growth rate of that firm-destination. The results are presented in Table VIII, panel B. The contribution of the firmspecific component is still important. 
It may be that firms in different regions of France are subject to shocks specific to their geographical location. This could be because factor (or goods) markets are local, for instance. To check for this possibility, we implement an augmented model in which we add a geographic location-specific shock that affects all firms located in a particular geographic area within France. The definition of geographic area corresponds to the "employment zone" (zone d'emploi), which is intended to capture the extent of the local labor market. It is larger than a city (at least when the city is small), but smaller than a county. There are about 300 zones d'emploi in France. The results are reported in Table VIII, panel C. Adding shocks specific to the local labor market leaves the basic results unchanged.

All of the above results use a particular level of disaggregation (about 50 sectors, among them 22 manufacturing). It could be that sectoral shocks take place at a more detailed level. To check for this possibility, panel D in Table VIII implements the model under more finely disaggregated sectors: five-digit NAF, or about 700 distinct sectors. The results are virtually unchanged from the baseline.

Finally, as a different robustness check, panel E in Table VIII presents results when implementing the baseline model on 3-year average firm-destination growth rates instead of yearly growth rates. The results are robust to time aggregation. ${ }^{27}$

\section{CONCLUSION}

Do firm-level dynamics have an impact on aggregate fluctuations? Recent contributions argue that idiosyncratic shocks to firms can indeed manifest themselves in aggregate fluctuations if the firm size distribution is sufficiently fat-tailed (Gabaix (2011)) or when linkages propagate microeconomic shocks across firms leading to positive endogenous comovement (e.g., Acemoglu et al. (2012)). However, the empirical evidence supporting these different theories has been limited. This paper constructs a novel data set that merges French domestic and export sales at the firm level over the period 1990-2007, and provides a forensic account of the role of individual firms in generating aggregate fluctuations.

We begin by proposing a simple model, in the spirit of Melitz (2003) and Eaton, Kortum, and Kramarz (2011), to motivate an estimation framework that allows us to extract the macroeconomic, sectoral, and firm-specific components of a firm's sales to a given destination. These estimates are then aggregated up to explain the relative contribution of each component to the volatility of aggregate sales. Our main results can be summarized as follows. First, the firm-specific component accounts for an important part of the fluctuations of

\footnotetext{
${ }^{27}$ We also ran specifications restricting the sample to firms that exist for at least 8 years. Results were similar to the baseline specification, and are available from the authors upon request.
} 
aggregate sales growth. The standard deviation of the aggregated firm-specific shocks amounts to $80 \%$ of the standard deviation of aggregate sales in the whole economy and to $69 \%$ in the manufacturing sector. We interpret this as evidence for the relevance of firm-level shocks for aggregate fluctuations. Second, while the direct effect of firm shocks on aggregate volatility is quantitatively relevant, the majority of the contribution of firm shocks to aggregate fluctuations is accounted for by firm-to-firm covariance terms, which we interpret as evidence of linkages.

\section{REFERENCES}

Acemoglu, D., V. M. Carvalho, A. Ozdaglar, and A. Tahbaz-Salehi (2012): "The Network Origins of Aggregate Fluctuations," Econometrica, 80 (5), 1977-2016. [1303,1305,1306, $1313,1326,1330,1331,1337]$

BernaRD, A. B., S. J. REDDING, AND P. K. SCHOTT (2010): "Multiple-Product Firms and Product Switching," American Economic Review, 100 (1), 70-97. [1308]

BilbiIE, F. O., F. Ghironi, AND M. J. Melitz (2012): "Endogenous Entry, Product Variety and Business Cycles,” Journal of Political Economy, 120 (2), 304-345. [1308]

BLum, B. S., S. ClaRo, AND I. HoRSTMANN (2013): “Occasional and Perennial Exporters," Journal of International Economics, 90 (1), 65-74. [1334]

Caballero, R. J., E. M. R. A. Engel, And J. Haltiwanger (1997): "Aggregate Employment Dynamics: Building From Microeconomic Evidence," American Economic Review, 87 (1), 115-137. [1307]

Canals, C., X. Gabaix, J. M. Vilarrubia, AND D. E. Weinstein (2007): "Trade Patterns, Trade Balances, and Idiosyncratic Shocks," Working Paper 02/2007, la Caixa. [1305,1325]

CARvalho, V. M., AND X. GabaIX (2013): "The Great Diversification and Its Undoing," American Economic Review, 103 (5), 1697-1727. [1303,1306,1311,1316,1326]

CAstro, R., G. L. Clementi, AND Y. LeE (2013): "Cross-Sectoral Variation in Plant-Level Idiosyncratic Risk," Journal of Industrial Economics (forthcoming). [1304,1307,1312,1316, 1318]

CoHEN, L., AND A. FraZzINI (2008): "Economic Links and Predictable Returns,” Journal of Finance, 63 (4), 1977-2011. [1306]

COMÍN, D., AND T. PHILIPPON (2006): "The Rise in Firm-Level Volatility: Causes and Consequences," in NBER Macroeconomics Annual 2005, Vol. 20, ed. by M. Gertler and K. S. Rogoff. Cambridge, MA: MIT Press, Chapter 1, 167-201. [1307,1333]

CONLEY, T. G., AND B. DUPOR (2003): "A Spatial Analysis of Sectoral Complementarity," Journal of Political Economy, 111 (2), 311-352. [1303,1305,1306,1330]

CoOper, R., J. HAltiwanger, AND L. Power (1999): "Machine Replacement and the Business Cycle: Lumps and Bumps," American Economic Review, 89 (4), 921-946. [1307]

COOPER, R. W., AND J. C. HaltiWANGer (2006): "On the Nature of Capital Adjustment Costs," Review of Economic Studies, 73 (256), 611-633. [1307]

DAVIS, S. J., AND J. C. HALTIWANGER (1992): "Gross Job Creation, Gross Job Destruction, and Employment Reallocation," Quarterly Journal of Economics, 107 (3), 819-863. [1307]

DAVIS, S. J., R. J. FABERMAN, AND J. HALTiwANGer (2006): "The Flow Approach to Labor Markets: New Data Sources and Micro-Macro Links,” Journal of Economic Perspectives, 20 (3), 3-26. [1307]

Davis, S. J., J. C. Haltiwanger, And S. Schuh (1996): Job Creation and Destruction. Cambridge, MA: MIT Press. [1307,1335]

DAVIS, S. J., J. HALTIWANGER, R. JARMIN, AND J. MiRANDA (2007): "Volatility and Dispersion in Business Growth Rates Publicly Traded versus Privately Held Firms," in NBER Macroeconomics Annual 2006, Vol. 21, ed. by D. Acemoglu, K. Rogoff, and M. Woodford. Cambridge, MA: MIT Press, Chapter 2, 107-180. [1307] 
Di Giovanni, J., And A. A. Levchenko (2010): "Putting the Parts Together: Trade, Vertical Linkages, and Business Cycle Comovement," American Economic Journal: Macroeconomics, 2 (2), 95-124. [1313]

- (2012a): "Country Size, International Trade, and Aggregate Fluctuations in Granular Economies," Journal of Political Economy, 120 (6), 1083-1132. [1307,1333]

(2012b): "The Risk Content of Exports: A Portfolio View of International Trade," in NBER International Seminar on Macroeconomics, Vol. 8, ed. by J. Frankel and C. Pissarides. Chicago, IL: University of Chicago Press, Chapter 3, 97-151. [1312]

Di Giovanni, J., A. A. Levchenko, And I. MeJeAn (2014): "Supplement to 'Firms, Destinations, and Aggregate Fluctuations'," Econometrica Supplemental Material, 82, http://www.econometricsociety.org/ecta/supmat/11041_miscellaneous.pdf; http://www. econometricsociety.org/ecta/supmat/11041_data_and_programs.zip. [1307]

Di Giovanni, J., A. A. LevchenKo, AND R. RANCiÈRE (2011): "Power Laws in Firm Size and Openness to Trade: Measurement and Implications," Journal of International Economics, 85 (1), 42-52. [1326]

DiXIT, A. K., AND J. E. STIGLITZ (1977): "Monopolistic Competition and Optimum Product Diversity," American Economic Review, 67 (3), 297-308. [1333]

Doms, M. E., AND T. DunNe (1998): "Capital Adjustment Patterns in Manufacturing Plants," Review of Economic Dynamics, 1 (2), 409-429. [1307]

DUPOR, B. (1999): "Aggregation and Irrelevance in Multi-Sector Models," Journal of Monetary Economics, 43 (2), 391-409. [1303,1305,1306,1330]

EATON, J., S. S. Kortum, AND F. KRAmARz (2011): “An Anatomy of International Trade: Evidence From French Firms," Econometrica, 79 (5), 1453-1498. [1304,1308,1320,1337]

EAton, J., S. S. Kortum, B. NeIMAN, AND J. RomAlis (2011): "Trade and the Global Recession," Working Paper 16666, NBER. [1309]

FIRPO, S., N. M. ForTin, AND T. LemieuX (2011): "Decomposition Methods in Economics," in Handbook of Labor Economics, Vol. 4, ed. by O. Ashenfelter and D. E. Card. Amsterdam: Elsevier, 1-102. [1333]

Foerster, A. T., P.-D. G. SARte, AND M. W. WATSOn (2011): "Sectoral vs. Aggregate Shocks: A Structural Factor Analysis of Industrial Production,” Journal of Political Economy, 119 (1), 1-38. [1303,1306,1313,1326]

Fort, T. C., J. Haltiwanger, R. S. JARMin, AND J. MiRAndA (2013): "How Firms Respond to Business Cycles: The Role of Firm Age and Firm Size," IMF Economic Review, 61 (3), 520-559. [1333]

GABAIX, X. (2011): “The Granular Origins of Aggregate Fluctuations,” Econometrica, 79 (3), 733-772. [1303,1305,1307,1311-1313,1315,1316,1326,1328,1330,1337]

Gertler, M., AND S. Gilchrist (1994): "Monetary Policy, Business Cycles, and the Behavior of Small Manufacturing Firms," Quarterly Journal of Economics, 109 (2), 309-340. [1334]

GOURIO, F., AND A. K. KASHYAP (2007): "Investment Spikes: New Facts and a General Equilibrium Exploration,” Journal of Monetary Economics, 54 (Supplement), 1-22. [1307]

HALTiWANGER, J. C. (1997): "Measuring and Analyzing Aggregate Fluctuations: The Importance of Building From Microeconomic Evidence," Federal Reserve Bank of St. Louis Review, 79 (3), 55-77. [1304,1318]

HERTZEL, M. G., Z. LI, M. S. OfFICER, AND K. J. RODGERS (2008): “Inter-Firm Linkages and the Wealth Effects of Financial Distress Along the Supply Chain," Journal of Financial Economics, 87 (2), 374-387. [1306]

Horvath, M. (1998): “Cyclicality and Sectoral Linkages: Aggregate Fluctuations From Independent Sectoral Shocks," Review of Economic Dynamics, 1 (4), 781-808. [1303,1305,1306, 1330]

(2000): "Sectoral Shocks and Aggregate Fluctuations," Journal of Monetary Economics, 45 (1), 69-106. [1303,1305,1306,1330]

JovANOVIC, B. (1987): "Micro Shocks and Aggregate Risk," Quarterly Journal of Economics, 102 (2), 395-410. [1306] 
Kashyap, A. K., O. A. Lamont, And J. C. Stein (1994): "Credit Conditions and the Cyclical Behavior of Inventories," Quarterly Journal of Economics, 109 (3), 565-592. [1334]

KelLy, B., H. Lustig, AND S. VAN NieuwerbuRgh (2013): "Firm Volatility in Granular Networks," Report, University of Chicago, UCLA, and NYU. [1306]

KLETTE, T. J., AND Z. GRILICHES (1996): “The Inconsistency of Common Scale Estimators When Output Prices Are Unobserved and Endogenous," Journal of Applied Econometrics, 11 (4), 343-361. [1316]

Koren, M., AND S. TENREYRo (2007): "Volatility and Development," Quarterly Journal of Economics, 122 (1), 243-287. [1312]

Krugman, P. (1980): "Scale Economies, Product Differentiation, and the Pattern of Trade," American Economic Review, 70 (5), 950-959. [1333]

LEE, Y., AND T. MuKoYAma (2012): "Entry, Exit, and Plant-Level Dynamics Over the Business Cycle," Report, Sogang University, Federal Reserve Bank of Cleveland, and University of Virginia. [1307]

Long, J. B., AND C. I. Plosser (1983): “Real Business Cycles,” Journal of Political Economy, 91 (1), 39-69. [1303,1306]

MeliTZ, M. J. (2003): "The Impact of Trade on Intra-Industry Reallocations and Aggregate Industry Productivity," Econometrica, 71 (6), 1695-1725. [1304,1308,1333,1337]

MOSCARINI, G., AND F. POSTEL-VINAY (2012): "The Contribution of Large and Small Employers to Job Creation in Times of High and Low Unemployment," American Economic Review, 102 (6), 2509-2539. [1307,1316]

OsotimeHin, S. (2013): "Aggregate Productivity and the Allocation of Resources Over the Business Cycle," Report, University of Virginia. [1308]

SHEA, J. (2002): "Complementarities and Comovements," Journal of Money, Credit, and Banking, 34 (2), 412-433. [1303,1305,1306,1330]

StOcKman, A. C. (1988): "Sectoral and National Aggregate Disturbances to Industrial Output in Seven European Countries," Journal of Monetary Economics, 21, 387-409. [1303,1306,1312]

Thesmar, D., AND M. Thoenig (2011): "Contrasting Trends in Firm Volatility," American Economic Journal: Macroeconomics, 3 (4), 143-180. [1307]

Dept. of Economics and Business, Universitat Pompeu Fabra, Ramon Trias Fargas 25-27, 08005 Barcelona, Spain, Barcelona GSE, CREI, and CEPR; julian.digiovanni@upf.edu,

Dept. of Economics, University of Michigan, 611 Tappan Street, Ann Arbor, MI 48104, U.S.A., NBER, and CEPR; alev@umich.edu,

and

Dept. of Economics, Ecole Polytechnique, Routed de Saclay, 91128 Palaiseau cedex, France and CEPR; isabelle.mejean@polytechnique.edu.

Manuscript received August, 2012; final revision received April, 2014. 